ARTICLE

\title{
The Aurora B specificity switch is required to protect from non-disjunction at the metaphase/ anaphase transition
}

Joanna R. Kelly (Di) ${ }^{1,6}$, Silvia Martini ${ }^{1}$, Nicola Brownlow ${ }^{1,7}$, Dhira Joshi ${ }^{2}$, Stefania Federico ${ }^{2}$, Shirin Jamshidi (iD ${ }^{3}$, Svend Kjaer (10 ${ }^{4}$, Nicola Lockwood ${ }^{1}$, Khondaker Miraz Rahman (10 ${ }^{3}$, Franca Fraternali ${ }^{5}$, Peter J. Parker ${ }^{1,3 凶} \&$ Tanya N. Soliman (1) 1,8凶

The Aurora B abscission checkpoint delays cytokinesis until resolution of DNA trapped in the cleavage furrow. This process involves PKC $\varepsilon$ phosphorylation of Aurora B S227. Assessing if this $\mathrm{PKC} \varepsilon$-Aurora $\mathrm{B}$ module provides a more widely exploited genome-protective control for the cell cycle, we show Aurora B phosphorylation at $\mathrm{S} 227$ by PKC $\varepsilon$ also occurs during mitosis. Expression of Aurora B S227A phenocopies inhibition of PKC $\varepsilon$ in by-passing the delay and resolution at anaphase entry that is associated with non-disjunction and catenation of sister chromatids. Implementation of this anaphase delay is reflected in PKC $\varepsilon$ activation following cell cycle dependent cleavage by caspase 7; knock-down of caspase 7 phenocopies PKC $\varepsilon$ loss, in a manner rescued by ectopically expressing/generating a free PKC $\varepsilon$ catalytic domain. Molecular dynamics indicates that Aurora B S227 phosphorylation induces conformational changes and this manifests in a profound switch in specificity towards S29 Topollo phosphorylation, a response necessary for catenation resolution during mitosis.

\footnotetext{
${ }^{1}$ Protein Phosphorylation Laboratory, Francis Crick Institute, 1 Midland Rd, London NW1 1AT, UK. ${ }^{2}$ Peptide Chemistry Platform, Francis Crick Institute, 1 Midland Rd, London NW1 1AT, UK. ${ }^{3}$ School of Cancer and Pharmaceutical Sciences, King's College London, London, UK. ${ }^{4}$ Structural Biology Platform, Francis Crick Institute, 1 Midland Rd, London NW1 1AT, UK. ${ }^{5}$ Randall Centre for Cell and Molecular Biophysics, King's College London, London, UK. ${ }^{6}$ Present address: Cancer Research UK, Manchester Institute, Alderley Park SK10 4TG, UK. ${ }^{7}$ Present address: Instituto de Neurociencias, Av. Santiago Ramón y Cajal s/n 03550, San Juan de Alicante, Spain. ${ }^{8}$ Present address: Barts Cancer Institute, Queen Mary University London, Charterhouse Square, London EC1M 6BE, UK.

凶email: peter.parker@crick.ac.uk; t.soliman@qmul.ac.uk
} 
E ntry to and exit from mitosis is exquisitely controlled to ensure faithful propagation of the resultant daughter cells. Genome-protective pathways such as the MiDAS salvage pathway, engaged upon the detection of incomplete DNA replication at mitosis ${ }^{1}$, or the non-disjunction response ${ }^{2}$ have evolved in addition to cell cycle checkpoints to ensure the fidelity of division.

As a master regulator of mitosis, Aurora B has been ascribed functions throughout mitosis and cytokinesis ${ }^{3}$. We have previously described a switch in Aurora B substrate specificity after second site phosphorylation of the activation loop at $S 227^{4}$. Upon retention of chromatin in the cytokinetic furrow an Aurora Bdependent abscission checkpoint is engaged and protein kinase $\mathrm{C}$ epsilon $(\mathrm{PKC} \varepsilon)$ is required for exit once resolution of the lagging DNA strands occurs. Specifically, PKCe phosphorylates Aurora B at S227 which induces a switch in Aurora B substrate specificity, such that it then phosphorylates the adaptor protein Borealin at S165 ${ }^{4}$ to release the ESCRTIII component CHMP4C from a closed, inactive conformation to allow polymerisation of the ESCRTIII complex and successful completion of abscission ${ }^{5,6}$.

PKC $\varepsilon$-dependent pathways provide alternative, failsafe mechanisms for passage through mitosis. A conditional requirement for PKCe has been reported for bipolar spindle assembly ${ }^{7}$ and the metaphase response to catenation ${ }^{2}$ in a subset of transformed cell lines which lack a competent topoisomerase IIa (TopoIIa)-dependent G2 arrest. During metaphase, if the cell is challenged by excess catenation, $\mathrm{PKC} \varepsilon$ instigates a delay in anaphase entry through delayed spindle assembly checkpoint (SAC) silencing and mitigates dynein directed streaming of the RZZ complex ${ }^{2}$. The engagement of PKC $\varepsilon$ in these TopoIIa-dependent G2 arrest deficient cells occurs by an as yet, undefined mechanism.

Here we assess the penetrance of PKCe-Aurora B module action in responding to genomic stress by addressing the requirement at the metaphase-anaphase transition. We demonstrate that the switch in Aurora B substrate repertoire driven by PKCe-mediated phosphorylation of S227 during cytokinesis appears to also function during metaphase. This correlates with the Caspase-7 dependent proteolytic activation of PKCe. The phosphorylation of Aurora B at S227 induces a conformational change in the activation loop of the kinase and is required for the switch in substrate specificity of Aurora B. This allows selection of substrates required for satisfaction of the SAC and enhances TopoII a decatenation through phosphorylation of S29 promoting sister chromatid disjunction prior to anaphase entry.

\section{Results}

Chromosome disjunction requires Aurora B S227 phosphorylation. To assess the dependence on the phosphorylation of Aurora B S227 for mitotic fidelity we introduced the nonphosphorylatable GFP-Aurora B S227A mutant into DLD1 cells. This results in an increase in the number of cells with aberrantly shaped nuclei (Fig. 1a) suggesting chromosome non-disjunction events, consistent with previous reports of an increase in binucleate cells observed on expression of Aurora B S227A ${ }^{4}$. There is also an increase in DAPI-positive bridges and PICHpositive strands present in anaphase cells (Fig. 1b). This bridging phenotype is associated with unresolved sister chromatid intertwines, indicative of catenation ${ }^{8}$. Direct assessment of this by removal of centromeric cohesion through knockdown of Shugoshin 1 (Sgo1) (Fig. 1c), showed that a significant increase in retained sister chromatid pairs was observed (Fig. 1d), comparable with knockdown of TopoIIa. We have previously demonstrated that this association between sister chromatid pairs is dependent on TopoIIa as post-extraction treatment of metaphase spreads with recombinant TopoIIa results in rescue of this phenotype to control levels ${ }^{2}$.
A PKC $\mathrm{P}$-dependent pathway responds to the retention of metaphase catenation in transformed cells with a defective TopoIIa-dependent G2 checkpoint ${ }^{2}$. On TopoIIa inhibition with ICRF193, DLD1 cells delay anaphase entry and in the absence of PKC $\varepsilon^{2}$ or with the expression of Aurora B S227A (Fig. 1e) this delay is compromised, consistent with the idea that Aurora B is operating on this pathway downstream of PKCE. In the presence of catenation, inhibition of $\mathrm{PKC} \varepsilon$ activity in a mitotically enriched population of cells (Supplementary Fig. 1a) with either BLU577 (Fig. 1f) or BIM1 (Supplementary Fig. 1b) resulted in a significant reduction in Aurora B S227 phosphorylation by immunoblot. Notably, there is no change in phosphorylation of Aurora B S227 in asynchronously growing cultures treated with PKC inhibitors (Supplementary Fig. 1c), indicating that under these conditions, this site is phosphorylated by an as yet unidentified kinase. The reduction in phosphorylation in mitotic extracts that we observe with $\mathrm{PKC}$ inhibition shows that this $\mathrm{PKC} \varepsilon$-Aurora $\mathrm{B}$ regulatory module is cell cycle dependent, occurring in mitosis, as well as cytokinesis as previously described ${ }^{4}$.

Expression of the non-phosphorylatable Aurora B mutant does not preclude the SAC response in these cells as they still mount a checkpoint arrest in the presence of the microtubule assembly inhibitor nocodazole (Fig. 1g). The metaphase catenation response is characterised by $\mathrm{MAD} 2^{\text {low }} / \mathrm{Bub} 1^{\text {high }} / \mathrm{BubR} 1^{\text {high }}$ kinetochore staining, which is sensitive to PKCE loss or inhibition ${ }^{2}$. After ICRF193 treatment of DLD1 cells, BubR1 is maintained at the kinetochore in the Aurora B wild type expressing cells but not in those expressing Aurora B S227A, accounting for the delay in anaphase entry and bypass of the delay respectively (Fig. 1h). Nevertheless, cells expressing Aurora B S227A mount a SAC response in response to nocodazole inducing rapid relocalisation of BubR1 to the kinetochore in these cells. Consistent with a normal implementation of the SAC, MAD2 and BubR1 are localised to the kinetochore during prometaphase in these cells, but MAD2 is absent in metaphase cells irrespective of ICRF193 treatment or expression of Aurora B S227A (Fig. 1i).

A chromatin-associated pool of PKC $\varepsilon$ is cleaved in mitosis. We sought to determine the mechanism by which the PKCe-Aurora $\mathrm{B}$ regulatory module operates at the metaphase-anaphase transition. We find there are sub-populations of GFP-PKCe present; a centrosomal, spindle-associated pool that we have previously described $^{7}$ as well as a chromatin-associated compartment that can be visualised by immunofluorescence (Fig. 2a) and appears to be enriched during metaphase. Upon fractionation of mitotic cell extracts, it was apparent that within this latter compartment GFP-PKCE was partially fragmented, as evident in the appearance of two faster migrating, immunoreactive bands at 35 and $43 \mathrm{kDa}$ recognised by a C-terminal $\mathrm{PKC} \varepsilon$ antibody (Fig. 2b). An Nterminal cleavage fragment could be detected also by probing for GFP (Fig. 2b). PKCe has been previously reported to be phosphorylated during mitosis at S346, S350, S368 to facilitate 14-3-3 binding ${ }^{9}$, resulting in slower migration of full length PKC $\varepsilon$ bands by western blot of the TritonX-100 soluble fraction (Supplementary Fig. 2a). The lower molecular weight species observed in the insoluble fraction were verified as $\mathrm{PKC} \varepsilon$ as these bands could no longer be detected by western blotting after RNAi-mediated depletion of PKCE (Supplementary Fig. 2a). We demonstrate mitosis-specific cleavage of both endogenous (Supplementary Fig. 2b) and exogenously expressed (Supplementary Fig. 2c) PKC $\varepsilon$ across multiple cell lines, indicating that this is a widespread event. Some cleavage of PKCe is evident in asynchronously cycling cells and we attribute this observation to the presence of mitotic cells in these cultures. The observed cleavage of PKCe is chromatin associated (Supplementary Fig. 2d) and 
a

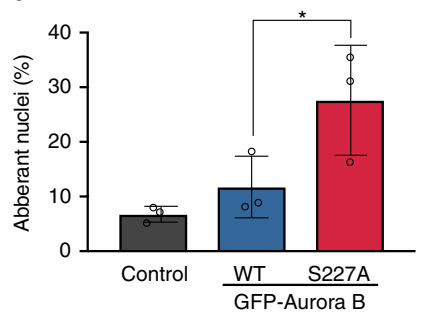

b

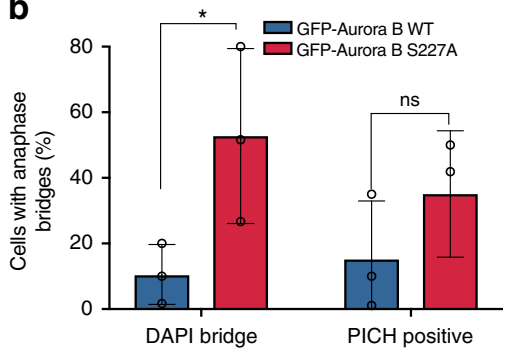

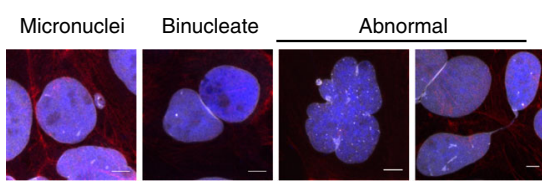

d

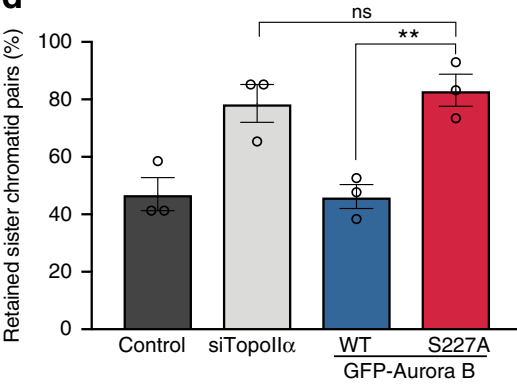

$\mathbf{f}$

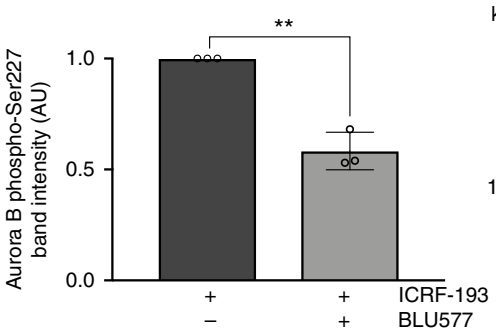

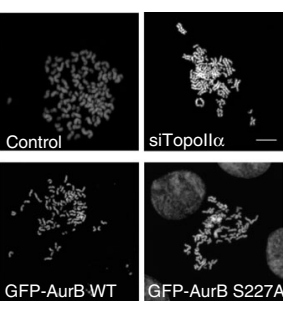

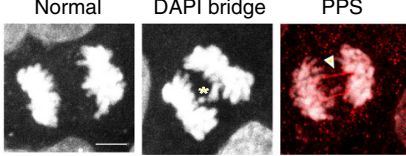

C

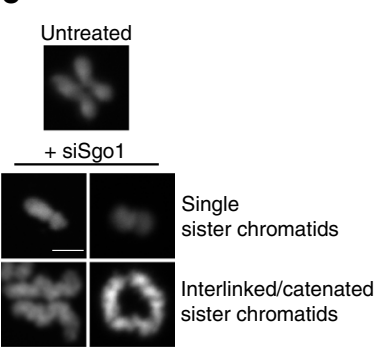

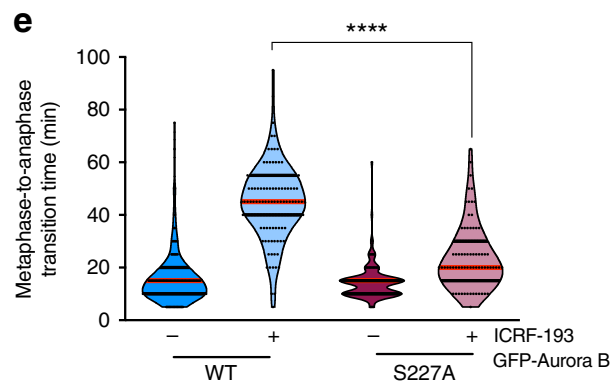

g

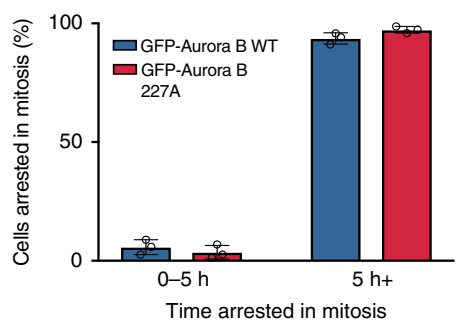

Time arrested in mitosis

h
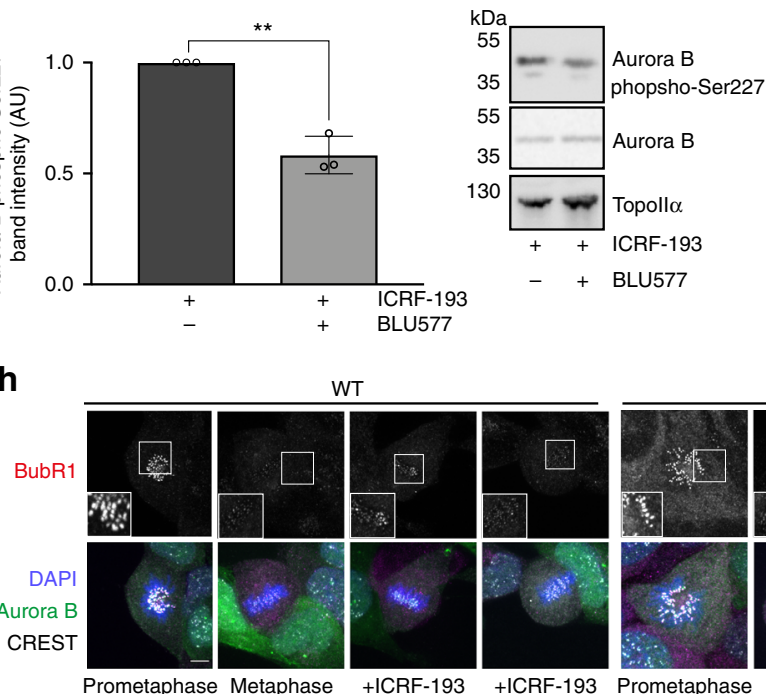

WT
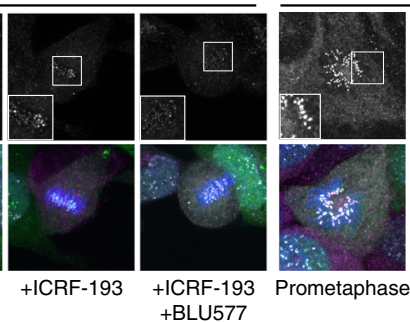

S227A

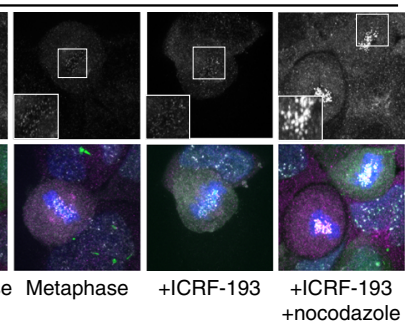

i
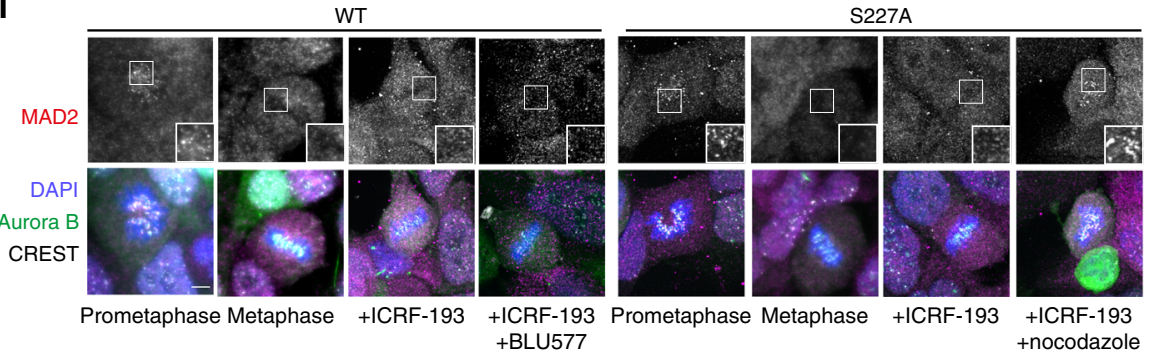

mitosis specific, evidenced by an enrichment of these cleavage products in prometaphase synchronised cells (Supplementary Fig. 2e). Enrichment in G1/S or G2 phase did not yield these faster migrating cleaved species (Supplementary Fig. 2f). Inhibition of PKCe using the selective inhibitor BLU5772,4,10 did not influence proteolytic cleavage nor did inhibition of TopoIIa, known to engage a PKCe dependent mitotic pathway ${ }^{2}$ (Supplementary Fig. 2g). The fragment produced is characterised by phosphorylation on key priming sites and these modifications are essential for catalytic competence (Supplementary Fig. 2h) ${ }^{11}$. 
Fig. 1 Phosphorylation of Aurora B S227 is required to support the metaphase response to catenation. a DLD1 cells expressing GFP-Aurora B wild type or S227A were scored for nuclear morphology. The mean \pm SD of three independent experiments is graphed $(n=\geq 200)$ (one-way ANOVA, $P=\leq 0.024$; Control $6.76 \% \pm 1.46$, WT $11.76 \% \pm 5.63$, S227A 27.63\% \pm 10.07 ). Scale bar $=5 \mu \mathrm{m}$. b Anaphase cells were scored for DAPI-positive bridges or PICH-positive strands. The graph represents the mean \pm SD of three independent experiments, $>20$ cells per condition were scored per experiment (two-tailed Students' $t$ test, ${ }^{\star} P=0.027$, DAPI: WT 10.35\% \pm 7.49 , S227A 46.02\% $\pm 25.62, \mathrm{PICH}:$ WT 17.18\% \pm 14.8, S227A 35.98\% \pm 15.83$)$. Scale bar $=5 \mu \mathrm{m}$. c Representative images of single sister chromatids or retained/catenated sister chromatids after $24 \mathrm{~h}$ Shugoshin knockdown (siSgo). Scale bar $=2 \mu \mathrm{m}$. $\mathbf{d}$ Cells were scored for the percent retained (catenated) sister chromatids. The mean \pm SEM of three experiments where $\geq 15$ cells per experiment were analysed is graphed (one-way ANOVA; ${ }^{\star \star} P=0.0061$; siControl 47.05\% \pm 5.75 , siTopoll $178.84 \pm 6.61$, WT $46.23 \pm 4.13$, S227A 83.21 \pm 5.561 ). Scale bar $=5 \mu \mathrm{m}$. e DLD1 cells expressing GFP-Aurora B wild type or S227A were treated $\pm 1 \mu \mathrm{M}$ ICRF193 immediately prior to time-lapse imaging and scored for time from metaphase to anaphase. Violin plots represent all cells scored, median in red. A minimum of 100 cells per condition in three independent experiments were analysed. (one-way ANOVA: $\left.{ }^{\star \star \star \star} P=\geq 0.0001\right)$. $\mathbf{f}$ Immunoblot of DLD1 cells (representative of three independent experiments) enriched in mitosis and treated with ICRF193 (1 $\mu$ M) \pm BLU577 (500 nM). TritonX-100 insoluble fractions were probed for Aurora B phospho-S227, total Aurora B, and Topoll $\alpha$. Mean \pm SD of the immunoblots is graphed (two-tailed Students' $t$ test; ${ }^{\star \star} P=0.001 ;+I C R F /+B L U 0.5835 \pm 0.085$ ). $\mathbf{g}$ Cells were treated with 500 nM nocodazole and imaged using live-cell timelapse microscopy for $24 \mathrm{~h}$ and scored for their time arrested in mitosis. The mean \pm SD of three experiments where $>50$ cells were analysed per condition, per experiment are graphed. Representative images of (h) BubR1 and (i) MAD2 kinetochore localisation after inducing a metaphase delay with ICRF193 (4 h, $1 \mu$ M) \pm BLU577 (20 min $500 \mathrm{nM}$ ) or \pm nocodazole $(5 \mathrm{~min}, 500 \mathrm{nM}$ ), from three independent experiments, a minimum of ten images were acquired. DAPI (blue), GFP-Aurora B (green), BubR1/MAD2 (magenta), CREST (white). Scale bar $=5 \mu \mathrm{m}$.

Non-canonical Caspase-7 cleavage of PKCe. Previously, PKCe has been reported to be cleaved by Caspase- 7 in vitro and this is associated with a pattern of fragmentation consistent with that observed here ${ }^{12}$. The sites of cleavage were mapped to D383, located in the V3 hinge region, and D451, in the $a-C$ helix of the kinase domain (see schematic, Fig. 2c). The consequence of cleavage at the D383 site is the liberation of a free kinase domain which relieves $\mathrm{PKC} \varepsilon$ from auto-inhibition. We therefore sought to examine whether this was the mechanism of cell cycledependent PKCe cleavage in vivo. Cleavage of PKCe to the 43 $\mathrm{kDa}$ free kinase domain was significantly inhibited by treatment of cells with the pan-Caspase inhibitor z-vad-FMK (Supplementary Fig. 3a). Knockdown of Caspase- 7 resulted in a $64 \%$ reduction of the cleaved, TritonX-100 insoluble PKC $\varepsilon$ species, however no significant reduction in cleavage was observed with depletion of Caspase-3 (Fig. 2d), suggesting a predominantly Caspase-7 dependent pathway, in agreement with observations by Basu et al. ${ }^{12}$. We note here, that the cleavage is not an equilibrium event it is unidirectional, hence it is difficult to achieve a more penetrant blockade as the residual activity ratchets towards cleavage.

We observed no evidence of an apoptotic programme being triggered associated with or consequent to Caspase-7 cleavage of PKC $\varepsilon$. Treatment of cells with ICRF193 or nocodazole did not affect cell viability (Supplementary Fig. $3 \mathrm{~b}$ ) nor did it induce cleavage of the apoptotic marker, poly (ADP ribose) polymerase (PARP) (Supplementary Fig. 3c). We observe cleavage of Caspase-7 to its active form in cells arrested in prometaphase but not those enriched in G1/S or G2 phases (Supplementary Fig. 3d).

We then investigated whether the Caspase-7-dependent cleavage of $\mathrm{PKC \varepsilon}$ was required to sustain the metaphase catenation response. It was found that Caspase-7 knockdown led to a substantial loss of the metaphase delay (Fig. 2e), similar to that observed with expression of the Aurora B S227A mutant (Fig. 1e). Importantly, this was rescued by the expression of the kinase domain of PKCE indicating that this is the necessary pathway operating under the control of Caspase-7 (Fig. 2f). Collectively the data indicate an apoptosis-independent role for Caspase-7 of which PKCe is the critical target in this cell cycle pathway and that cleavage of PKCe to release the kinase domain is required for the ICRF193-induced delay in the metaphase-anaphase transition.

PKCE cleavage protects from chromosome non-disjunction. Mutation of the aspartate residues identified as Caspase-7 cleavage sites by Basu et al. ${ }^{12}$ to asparagine, demonstrated that these are also the sites of mitotic cleavage (Fig. 3a). The expressed cleavage-site mutants were phosphorylated on the PKCe priming sites indicating that loss of catalytic competence did not appear to underlie the non-cleavage (Supplementary Fig. 4a, b). We then assessed the biological significance of this active catalytic fragment of PKCe that had been cleaved at D383 and in particular its potential role in the metaphase catenation-associated cell cycle delay, since we know that this pathway shows dependence on PKCe.

We engineered a DLD1 cell line to express inducible, GFPtagged PKCe where the cleavage sites have been mutated (Supplementary Fig. 4c). Endogenous PKCe is depleted in experiments where GFP-PKCe is induced to ensure results are not confounded by the dominant behaviour of the cleaved fragment. These cell lines were characterised and expression of the GFP-PKC $\varepsilon$ mutants does not affect the SAC (Supplementary Fig. 4d) nor induce PARP cleavage (Supplementary Fig. 4e), further suggesting the observed cleavage of PKCe was independent of a pro-apoptotic role of Caspase-7. By blocking the cleavage at D383 (with or without a block to cleavage at D451), we observed an increase in the number of cells exhibiting aberrantly shaped nuclei (Fig. 3b). Loss of cleavage was also associated with an increase in both DAPI-positive chromosome bridges and $\mathrm{PICH}$-positive strands, indicative of chromosome non-disjunction errors (Fig. 3c), phenocopying Aurora B S227A expression. Furthermore, cleavage of $\mathrm{PKC} \varepsilon$ was required to support resolution of catenation (Supplementary Fig. 4f), as the non-cleavable $\mathrm{PKC} \varepsilon$ failed to promote resolution of catenation in metaphase (Fig. 3d). We cannot conclusively exclude the presence of ultra-fine bridges or retention of cohesin as a contributing cause of sister chromatid non-disjunction due to technical limitations of available reagents; however, the presence of nondisjoined sister chromatids was rescued in vitro with recombinant TopoII a, as we have demonstrated previously ${ }^{2}$. The increment of retained sister chromatid pairs that is reversed by treatment with recombinant TopoIIa in vitro provides a robust functional assay for the extent of association dependent upon catenation. This is certainly not $100 \%$ of all non-disjunction events which may indeed include other modes of sister chromatid association such as a cohesin-removal defect ${ }^{13,14}$, but these are not impacted by the $\mathrm{PKC} \varepsilon$-Aurora $\mathrm{B}$ pathway reported here.

The metaphase catenation response requires cleaved PKCE. In cell lines where cleavage to the free kinase domain was prevented (D383N and D383/451N mutants), a loss of the characteristic 

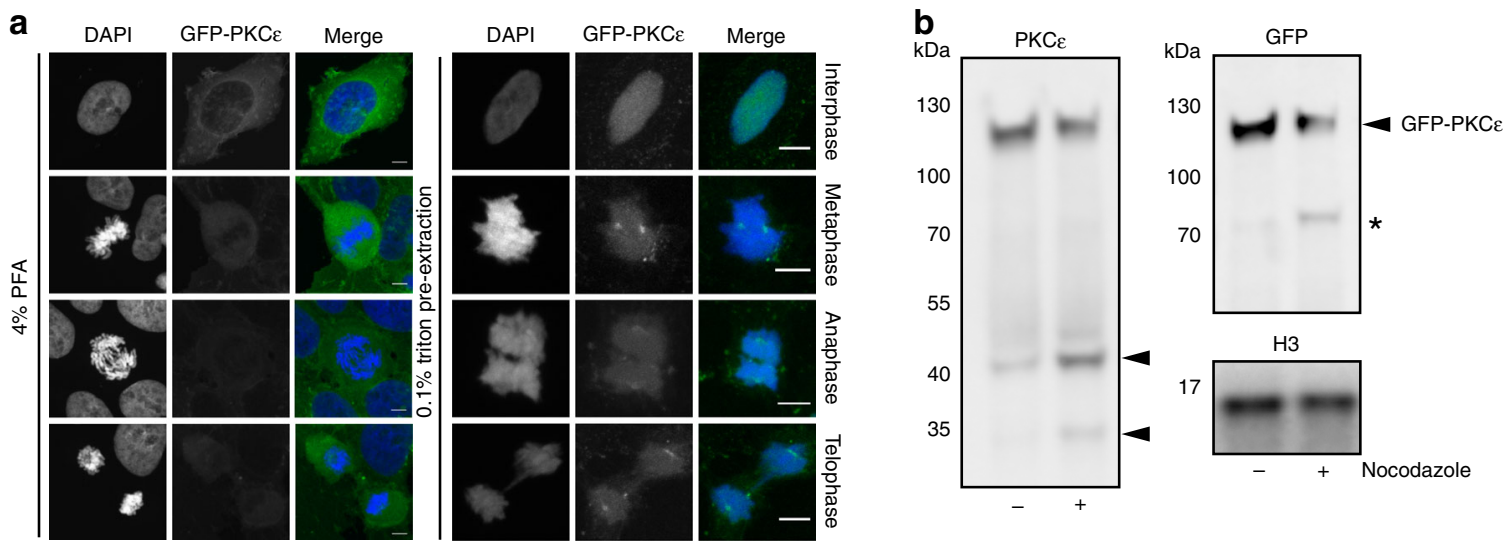

C
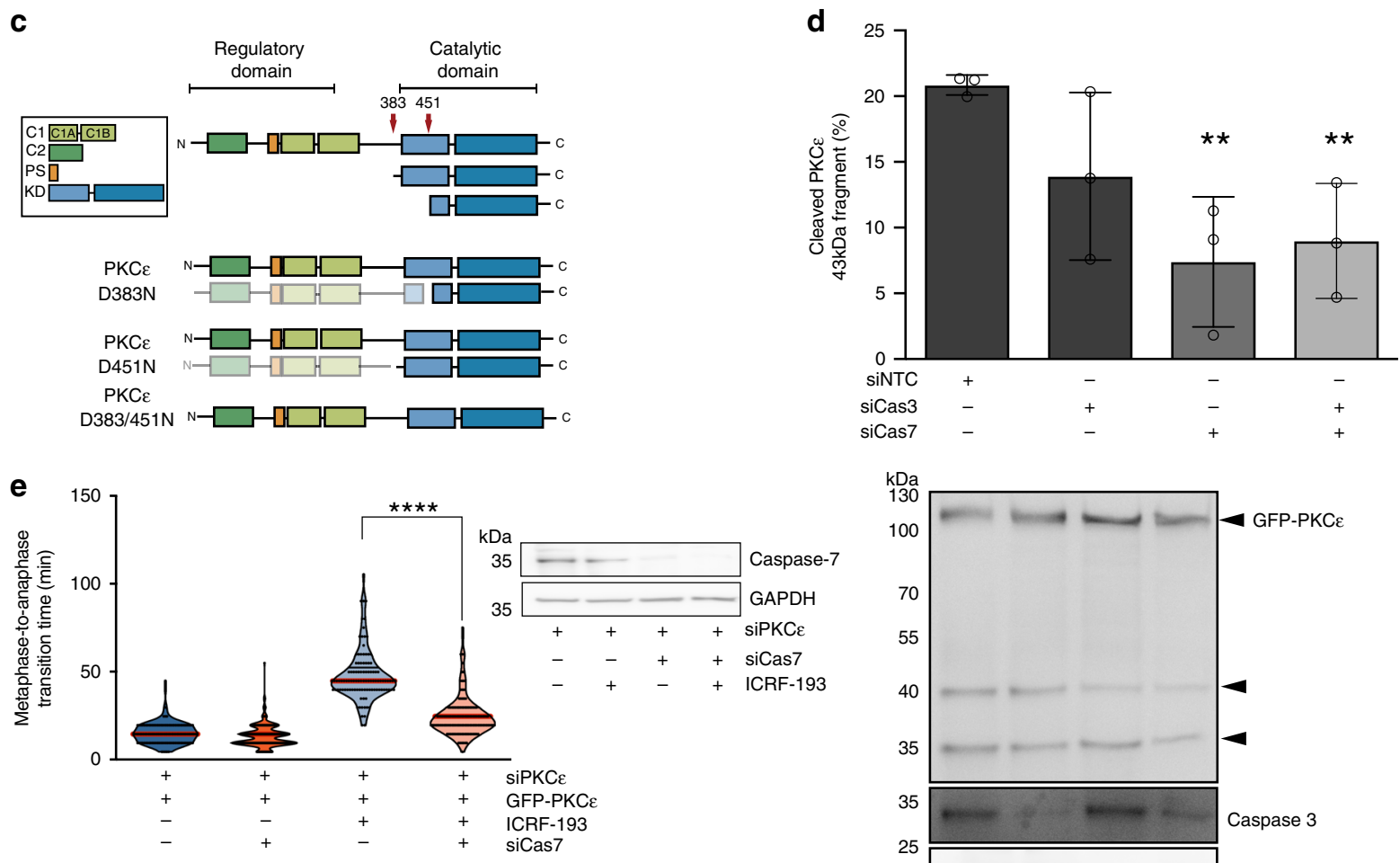

f
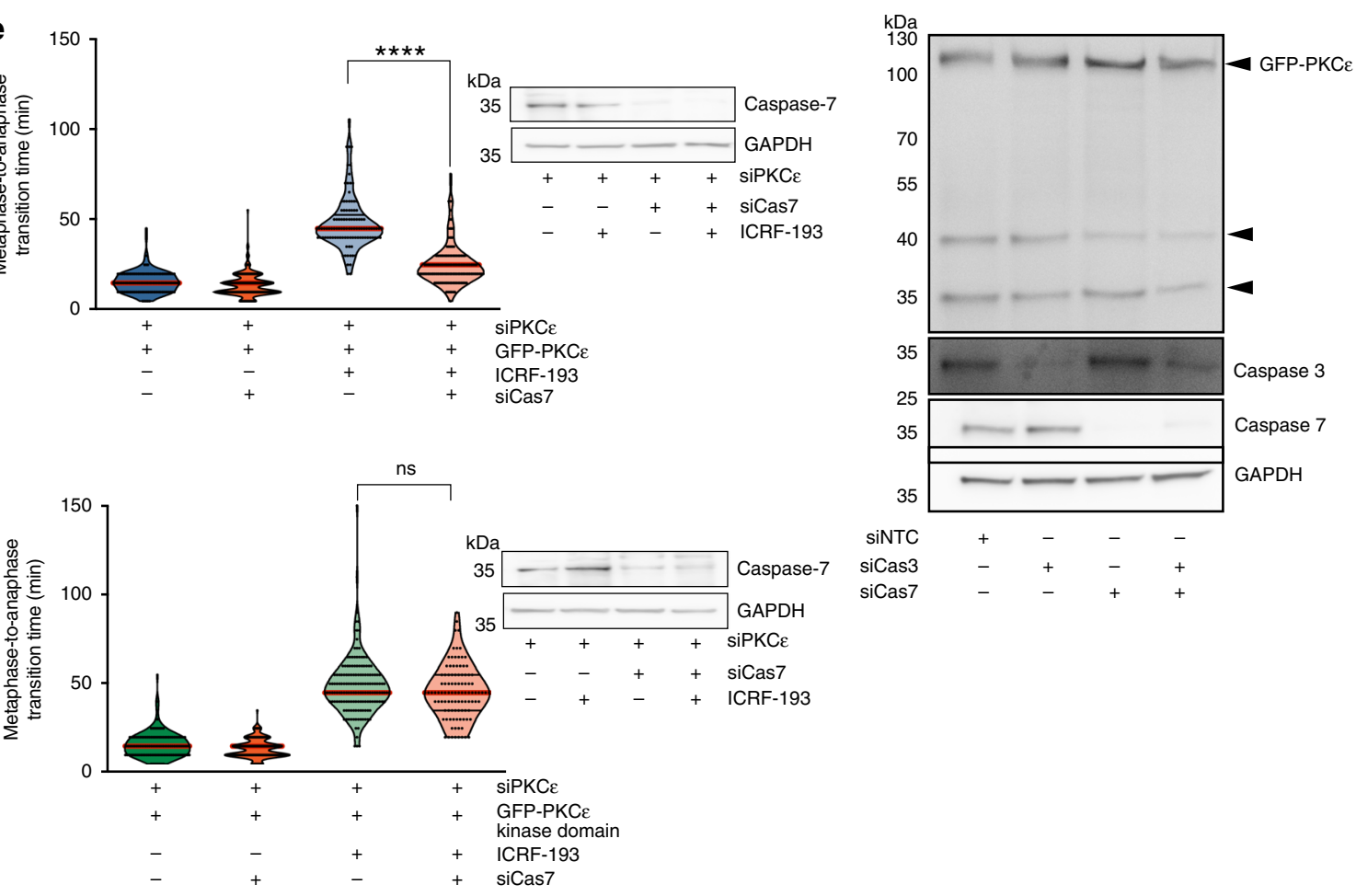

ICRF193-induced delay to anaphase entry was observed (Fig. 3e). To assess whether the cleavage product of PKCE is sufficient to support the metaphase functions of PKCe, we expressed the PKCe kinase domain in cells where the endogenous PKC $\varepsilon$ had been depleted (Fig. 3f, Supplementary Fig. 4g). Interestingly, the catalytic domain of PKCE is sufficient to maintain both the catenane resolution pathway (Supplementary Fig. 4f) and the ICRF193induced delay to anaphase entry (Fig. 3f). The cleavage product was able to fully recover PKCe functionality in both pathways after siRNA knockdown and there was no change to the metaphase duration or the number of catenated sister chromatids compared with the control. This suggested an essential role for 
Fig. 2 A chromatin-associated pool of PKC $\varepsilon$ is cleaved by Caspase-7 in mitosis. a Pre-extraction of cells with $0.1 \%$ Triton X-100 prior to fixation revealed a chromatin-associated pool of PKC $\varepsilon$. Images are representative of three independent experiments. Scale bar $=5 \mu \mathrm{m}$. $\mathbf{b}$ Triton $\mathrm{X}-100$ insoluble fraction of asynchronous or nocodazole $(500 \mathrm{nM})$ arrested DLD1 cell lysates were probed for PKCE, GFP, and Histone H3. Western blot is representative of three independent experiments. c Schematic of PKC $\varepsilon$ domains and cleavage products with putative cleavages sites described by Basu et al. ${ }^{12}$ marked by red arrows. d Immunoblot of GFP-PKC $\varepsilon$ to assess cleavage after knockdown of Caspases 3 and 7. Graph denotes the mean \pm SD of three independent experiments where the proportion of cleaved $43 \mathrm{kDa}$ fragment of PKC $\varepsilon$ present in the immunoblots was determined by densitometry (two-tailed Students' $t$ test; ${ }^{*} P=0.01$; siControl $20.85 \pm 0.76$, SiCas3 13.9 \pm 6.38 , siCas7 7.4 \pm 4.95 , siCas3 + siCas7 8.98 \pm 4.37 ). DLD1 cells were depleted of Caspase-7 and induced to express (e) GFP-PKC $\varepsilon$ wild type or (f) GFP-PKC $\varepsilon$ kinase domain and assessed for their response to metaphase catenation. Cells were treated with $\pm 1 \mu \mathrm{M}$ ICRF193 immediately prior to time-lapse imaging and scored for the time to progress from metaphase to anaphase. Violin plots represent all cells scored, the median is in red. A minimum of 100 cells per condition in three independent experiments were analysed. (One-way ANOVA, $\left.{ }^{\star \star \star \star} P=\leq 0.0001\right)$. Caspase-7 knockdown was confirmed by immunoblot for each experiment.

PKCe catalytic fragment production in execution of both the catenation-associated metaphase delay and also a catenation resolution pathway.

To address any potential confounding effect associated with the prolonged, constitutive expression of this kinase domain, we established expression of a rapamycin-inducible TEV-cleavage mutant of PKCE that permitted timed cleavage of the protein (Fig. 3g, h) ${ }^{15,16}$. As for the constitutively expressed kinase domain, metaphase induced cleavage was able to support the delay to anaphase entry (Fig. 3i). Hence the cell cycle associated cleavage of $\mathrm{PKC} \varepsilon$ to generate an active kinase domain is sufficient for the implementation of these metaphase-anaphase transition controls and reveals a Caspase-7-dependent PKCe-Aurora B signalling module.

Aurora B switches specificity to modify two sites on TopoIIa. TopoIIa has been identified as a classical PKC substrate in previous studies ${ }^{17-19}$ and this was determined to be a cell cycle phase specific phosphorylation of the residue S2918. We generated a phospho-specific antibody against this site to determine whether TopoIIa S29 could be a target of signalling through the mitosisderived PKCe catalytic fragment. Phosphorylation of TopoII at S29 was observed to be most prevalent during metaphase and to a lesser extent during anaphase; however it is completely absent at cytokinesis and in non-mitotic cells (Fig. 4a). Phosphorylation of S29 was significantly reduced after PKCe inhibition with BLU577 (Fig. 4b). Strikingly, TopoIIa S29 phosphorylation was substantially more reduced after Aurora B inhibition with ZM447439 (Fig. 4b), suggestive of TopoIIa being a downstream target of the $\mathrm{PKC} \varepsilon$-Aurora B signalling module.

A direct relationship between Aurora B and TopoIIa has also previously been described ${ }^{20}$. In agreement with the observations of Coelho et al., we detect co-localisation of Aurora B and TopoII $\alpha$ at the centromere in metaphase cells (Supplementary Fig. 5a). The centromeric localisation of TopoIIa was lost upon Aurora B knockdown and became more diffuse with expression of Aurora B S227A suggesting a functional relationship with the PKC $\varepsilon$-Aurora $\mathrm{B}$ node. We sought to determine whether active Aurora B (both the pT232 and the pS227/pT232 phosphorylated forms) could phosphorylate TopoIIa initially using peptide arrays of the protein (Fig. 4c, d). Remarkably, the two phospho-species of Aurora B displayed distinct preferences for the phosphorylation of TopoIIa. The recombinant Aurora B wild type protein (pS227/pT232) predominantly phosphorylated TopoIIa S29 while the Aurora B S227A mutant (only phosphorylated on T232 in the activation loop) chiefly phosphorylated the T1460 site (Fig. 4c, d). This preference in substrate sites was also displayed in the phosphorylation of recombinant TopoIIa in vitro (Fig. 4e, Supplementary Fig. 5b). We further validated these as being bona fide, cell cycle regulated phosphorylation sites in cells by immunoblot and immunofluorescent microscopy (Supplementary Fig. 5c-f). Notably, we confirmed TopoIIa S29 as a substrate of the PKCe-Aurora B signalling module in cells as phosphorylation at this site is significantly diminished upon expression of either the non-cleavable PKCe D383/451N or Aurora B S227A (Fig. 4f, g).

Detection of phosphorylation at TopoIIa T1460 was confounded by the fact that the phospho-T1460 antibody alone was not amenable to standard immunofluorescent staining methods, however detection by proximity ligation assay (PLA) when paired with a pan-TopoIIa antibody allowed visualisation of the localisation of T1460-phosphorylated TopoIIa. Phosphorylation of the T1460 site appears to occur in both mitotic and nonmitotic cells to varying degrees but nevertheless dependent on Aurora B as the PLA signal is diminished upon treatment with ZM447439 (Supplementary Fig. 5f). We validated the signal from the antibody pairs by peptide competition and were no longer able to detect signal in the presence of peptide with the phosphorylated-T1460 residue (Supplementary Fig. 5f).

Aurora B S227 influences activation loop dynamics. The profound switch in Aurora B specificity towards TopoIIa led us to examine the differences in the predicted kinase structure and the dynamics underlying the switch in Aurora B substrate specificity using molecular dynamics simulations. A $100 \mathrm{~ns}$ molecular dynamics simulation was carried out to explore the role of phosphorylation of Aurora B pS227 on the dynamics of the protein and the conformation of the activation loop. The simulations were carried out in the ATP-bound form and in the presence of the INCENP C-terminal domain. During the course of the MD simulation, the loop region of the Aurora B pT232 form appeared to be more flexible than the Aurora B pS227/ pT232 form (Supplementary Fig. 6a). Principal component analysis (PCA) highlights that the conformation of the loop in Aurora pS227/pT232 is noticeably different from the loop in Aurora B pT232. The RMSF fluctuations of PC1, PC2, and PC3 show different dynamics in the pS227/pT232 form of Aurora $\mathrm{B}$ as well as a change in motion in the activation loop and INCENP (Supplementary Fig. 6b).

The dominant conformations of the pT232 and pS227/pT232 Aurora B enzymes (Supplementary Fig. 6c), extracted from the $\mathrm{MD}$ trajectories, were used for the molecular docking of peptides containing TopoIIa S29 and T1460 residues to assess the switch in substrate specificity observed for the pT232/pS227 Aurora B enzyme. The peptide containing TopoIIa S29 was able to bind to the groove in C-lobe of the protein structure next to the ATPbinding pocket of the dominant form of pS227/pT232 Aurora B but the monophosphorylated pT232 Aurora B dominant form could not accommodate the peptide. Similarly, the peptide containing T1460 residue docked within the binding pocket close to the ATP-binding site of pT232 Aurora B. However, this peptide occupied a much lower position and with inappropriate orientation in the pS227/pT232 Aurora B. The peptide docking was followed by $100 \mathrm{~ns} \mathrm{MD}$ simulations to further explore the 
a

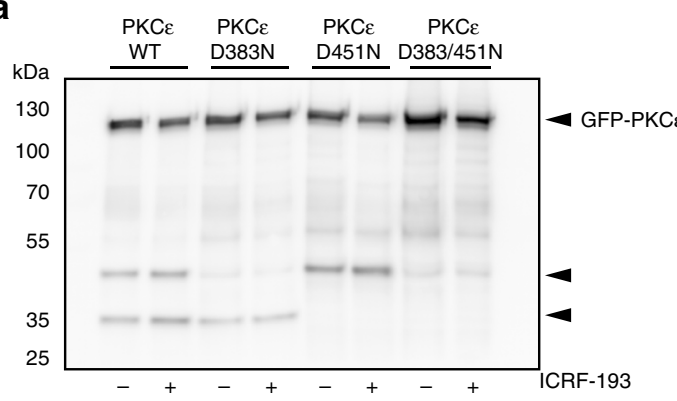

C

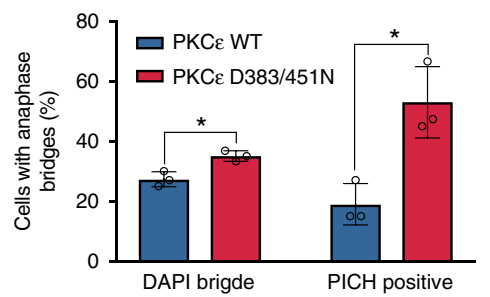

e

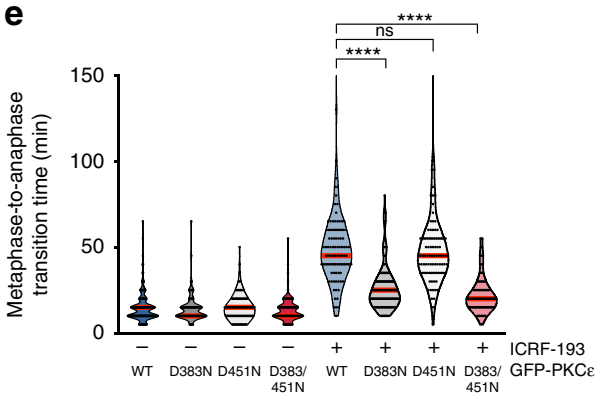

g

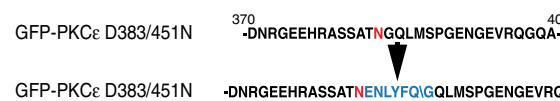
GFP-PKCE D383/451N -DNRGEEHRASSATNENLYFQIGQLMSPGENGEVRQGQA+ TEV protease site
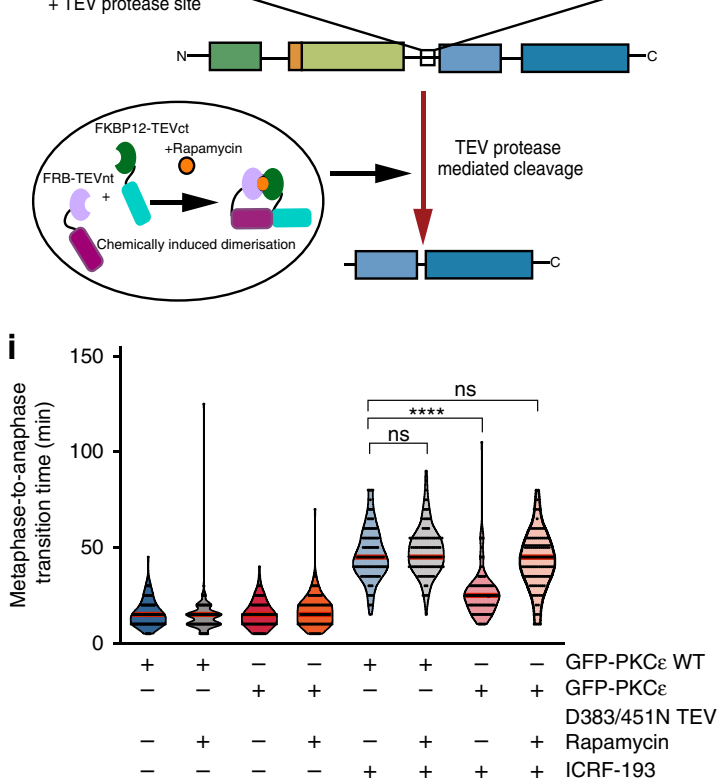

b

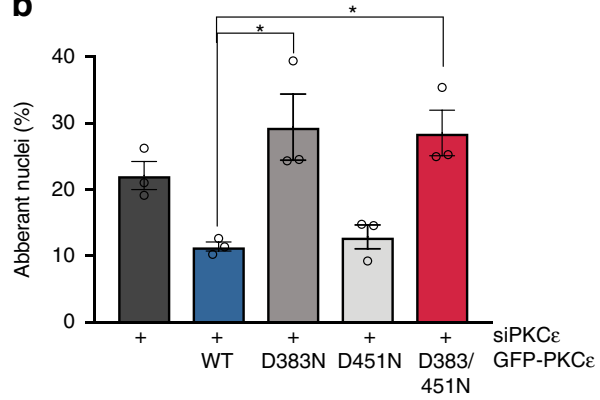

d

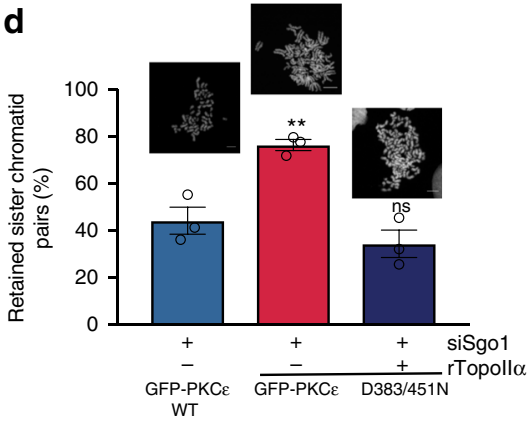

f

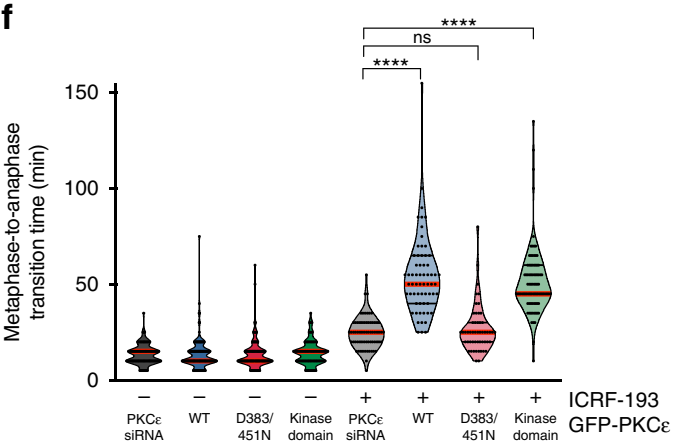

h

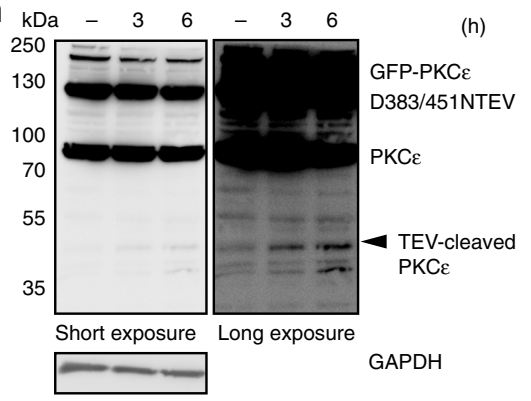

interactions between the peptides and the critical residues of the enzyme. As the catalytic mechanism of Aurora B involves acidifying the incoming $\mathrm{OH}$ of the substrate by aspartic acid of HRD motif, the distance between Asp200 of the motif and the OH group of TopoIIa S29 and T1460 residue was monitored throughout the course of the simulation. The initial distance for the pT232 substrate T1460 residue was $10.768 \AA-$ the MD simulation then pulled the substrate peptide closer to the ATP site, and the distance was reduced to $4.203 \AA$ (Supplementary Fig. 7a, b). A similar phenomenon was observed for the pT232/ 
Fig. 3 Cleaved PKC $\varepsilon$ is required for the metaphase catenation response. a Immunoblot of the TritonX-100-insoluble fraction of DLD1 cells expressing GFP-PKC $\varepsilon$ cleavage-site mutants, after arrest with nocodazole $(500 \mathrm{nM}) \pm$ ICRF193 $(1 \mu \mathrm{M})$ (representative of three independent experiments).

b DLD1 cells expressing GFP-PKC $\varepsilon$ wild type or cleavage mutants were scored for nuclear morphology. The mean \pm SD of three independent experiments is graphed $\left(n=\geq 200\right.$ cells per condition, per experiment, two-tailed Students' $t$ test; ${ }^{\star} P=0.023$, ${ }^{\star \star} P=0.008 ;$ siPKC $\varepsilon 22.11 \% \pm 3.68, W T 11.4 \% \pm 1.21$, D383N 29.4\% \pm 8.64, D451N 12.85\% \pm 5.94, D383/451 N 28.53\% \pm 3.43$)$. c Anaphase DLD1 cells expressing GFP-PKC $\varepsilon$ wild type or D383/451N were scored for DAPI-positive bridges or PICH-positive strands. The mean \pm SD of three independent experiments is graphed ( $n=\geq 20$ cells per condition, per experiment) (two-tailed Students' $t$ test, ${ }^{\star} P=0.012$, DAPI:WT 27.33\% $\pm 2.52, \mathrm{D} 383 / 451 \mathrm{~N} 35.06 \% \pm 1.761, \mathrm{PICH}:$ WT 19\% $\pm 6.93, \mathrm{D} 383 / 451 \mathrm{~N} 53.01 \% \pm$ 11.88). $\mathbf{d}$ Cells scored for the percent retained (catenated) sister chromatids. The mean \pm SEM of three independent experiments is graphed ( $n=\geq 15$ cells per experiment) (One-way ANOVA; ${ }^{\star \star} P=\leq 0.0064$; WT 44.24\% $\pm 5.74, \mathrm{D} 383 / 451 \mathrm{~N} 76.43 \% \pm 2.36, \mathrm{D} 383 / 451 \mathrm{~N}+\mathrm{rTopolla} 34.4 \% \pm 5.83$ ) Scale bar $=5$ $\mu \mathrm{m}$. e DLD1 cells expressing GFP-PKC $\varepsilon$ wild type or cleavage mutants were treated $\pm 1 \mu$ M ICRF193 immediately prior to time-lapse imaging and scored for metaphase-to-anaphase transition time. Violin plots represent all cells scored. A minimum of 50 cells per condition in three independent experiments were analysed (One-way ANOVA, ${ }^{\star \star \star \star} P=\leq 0.0001 ; \mathrm{WT}+$ ICRF193 $46.26 \pm 4.62 \mathrm{~min}, \mathrm{D} 383 \mathrm{~N}+$ ICRF193 $25.51 \pm 1.32 \mathrm{~min}, \mathrm{D} 451 \mathrm{~N}+$ ICRF193 $48.9 \pm 1.18 \mathrm{~min}$, D383/451 N + ICRF193 $23.05 \pm 1.62 \mathrm{~min}$ ). f DLD1 cells expressing GFP-PKC $\varepsilon$ wild type, cleavage mutants or kinase domain were treated $\pm 1 \mu \mathrm{M}$ ICRF193 immediately prior to time-lapse imaging and scored for metaphase-to-anaphase transition time. Violin plots represent all cells scored. A minimum of 50 cells per condition in three independent experiments were analysed. (one-way ANOVA; ${ }^{\star \star \star \star} P=\leq 0.0001 ; \operatorname{siPKC} \varepsilon+$ ICRF193 $24.05 \pm 1.15$ min, WT + ICRF193 $55.71 \pm 2.3 \mathrm{~min}, \mathrm{D} 383 / 451 \mathrm{~N}+$ ICRF193 $24.92 \pm 2.46 \mathrm{~min}$, kinase domain $55.01 \pm 2.6 \mathrm{~min})$. $\mathbf{g}$ Schematic of split-TEV system. $\mathbf{h}$ Immunoblot (representative of three independent experiments) of DLD1 cells co-expressing GFP-PKCED383/451N \pm TEV recognition sequence and split-TEV (sTEVp) after \pm rapamycin $(100 \mathrm{nM})$ for 3 and $6 \mathrm{~h}$ to demonstrate TEV-dependent cleavage. i DLD1 cells expressing GFP-PKC $\varepsilon$ wild type or TEV-cleavage mutant were arrested with nocodazole $(3 \mathrm{~h}, 500 \mathrm{nM})$ followed by \pm rapamycin $(2 \mathrm{~h}, 100 \mathrm{nM})$. After nocodazole washout cells were treated $\pm 1 \mu \mathrm{M}$ ICRF193 immediately prior to time-lapse imaging and scored for metaphase-to-anaphase transition time. Violin plots represent all cells scored. A minimum of 100 cells per condition in three independent experiments were analysed (one-way ANOVA; ${ }^{\star \star \star \star P} P=\geq 0.0001 ; \mathrm{WT}+\mathrm{ICRF} 19347.15 \pm 0.82 \mathrm{~min}, \mathrm{WT}+\mathrm{ICRF} 193$ + Rapamycin $47.86 \pm 0.9 \mathrm{~min}$, D383/451NTEV + ICRF193 $25.25 \pm 1.15 \mathrm{~min}$, D383/451NTEV + ICRF93 + Rapamycin $44.95 \pm 1.35 \mathrm{~min})$.

pS227 substrate peptide TopoIIa S29, and the distance was reduced from 12.948 to $4.666 \AA$ (Supplementary Fig. 7a, b). The post-simulation distances suggest the $\mathrm{OH}$ of the substrate peptide is in close proximity of the Asp200 to initiate the catalytic cycle. However, in the case of TopoIIa S29 and pT232 Aurora B, and T1460 and pS227/pT232 Aurora B, the distances, both pre-and post-simulations, remained unfavourable for phosphorylation to occur (Supplementary Fig. 7c) and the orientation of the peptides remained unfavourable.

Aurora B phosphorylation of TopoIIa enhances decatenation. To examine the potential function of these Aurora B sites on TopoIIa, we engineered the DLD1 cell line to express inducible GFP-TopoIIa with the S29 and T1460 residues mutated to nonphosphorylatable alanine, both individually and in combination (Supplementary Fig. 8a). Interestingly, neither site mutant nor their combination influenced the implementation of a delay to anaphase entry in the presence of ICRF193 (Fig. 5a) suggesting a function for Aurora $\mathrm{B}$ and the phosphorylation of TopoIIa distinct from the regulation of the SAC (see above Fig. $1 \mathrm{~g}$, $\mathrm{h}$ and ref. ${ }^{2}$ ). We next investigated whether the two distinctive forms of Aurora B would influence the activity of recombinant TopoIIa in vitro. To ensure we could observe any effect of Aurora B phosphorylation, recombinant TopoIIa was titrated to sub-optimal decatenation activity (Supplementary Fig. 8b). Aurora B WT protein (pS227/ pT232) increased TopoIIa activity against catenated kinetoplast DNA, while the S227A mutant (i.e., not phosphorylated at S227) showed a reduced effect (Fig. 5b) despite both kinase preparations demonstrating comparable activity against the shared substrate, Histone H3 S10 (Supplementary Fig. 8c) ${ }^{4}$. This strongly suggests that phosphorylation of TopoIIa at the S29 site contributes to the resolution pathway. Further supporting this is the observation that in vivo, when decatenation is inhibited with ICRF193, phosphorylation at the S29 site persists beyond mitosis, into cytokinesis as well as being present in binucleated cells that have failed cytokinesis (Fig. 5c). To further explore the requirement for phosphorylation at these sites, we used the inducible DLD1 GFPTopoIIa cell lines and also engineered HEK293 cells to express inducible GFP-TopoIIa WT or mutant forms with either the single or paired sites compromised: S29A, T1460A, and S29/ T1460A (Supplementary Fig. 8d). We found that unlike the ectopic WT TopoIIa, mutant forms in either of these two phosphorylation sites prevented support of the resolution pathway and led to the accumulation of catenated chromosomes (Fig. 5d, e); in cells where S29 was unable to be phosphorylated, this was commensurate with an increase in cells with aberrant nuclear morphology (Supplementary Fig. 8e). GFP-TopoIIa was extracted from the inducible HEK293 cell lines (Supplementary Fig. 8f) to examine whether the non-phosphorylatable mutant TopoIIa could still decatenate kDNA in vitro. We demonstrate a diminished decatenation ability of both TopoIIa S29 mutants (S29A and S29/T1460A) (Supplementary Fig. 8f, g) indicating phosphorylation of TopoIIa S29 enhances the decatenating ability of the enzyme. Collectively, the data indicate a bifurcation of the described Caspase7-PKC $\varepsilon$-Aurora B pathway (Fig. 6). One arm of this pathway signals a delay in anaphase entry through $\mathrm{PKC} \varepsilon$ Aurora $\mathrm{B}$ regulation of SAC silencing in response to unresolved catenanes, whilst the other directly influences the behaviour of TopoIIa in relation to the resolution of catenation through S29 phosphorylation.

\section{Discussion}

We have defined a mechanism by which the key mitotic kinase, Aurora B, orchestrates safe passage through the metaphase-anaphase transition in the presence of catenation. The switch in Aurora B substrate repertoire after PKCe phosphorylation of the activation loop residue S227 has profound effects on conformation of the kinase and how it interacts with substrates. This was demonstrated by the distinct difference in preference between Aurora B phosho-species for the two phosphorylation sites on TopoIIa, S29, and T1460, and we identified S29 phosphorylation as being necessary for enhanced catenation resolution. In addition, we have determined the input upstream of Aurora B which involves a non-canonical Caspase-7 signalling pathway resulting in the proteolytic cleavage of PKC $\varepsilon$ in mitosis. This effectively disengages the kinase from the well-defined mechanism of activation initiated by lipid binding at the cell membrane, potentially allowing PKCE access to the chromatin compartment and Aurora B. The data describe a novel signalling cascade engaging a genome-protective module, the PKCe-Aurora B cascade, acting both to delay metaphase in response to catenation and to promote resolution of catenation present in metaphase. 
a
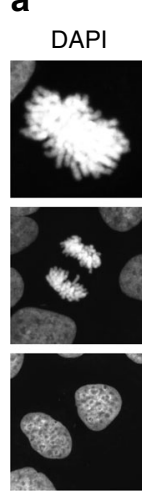

C
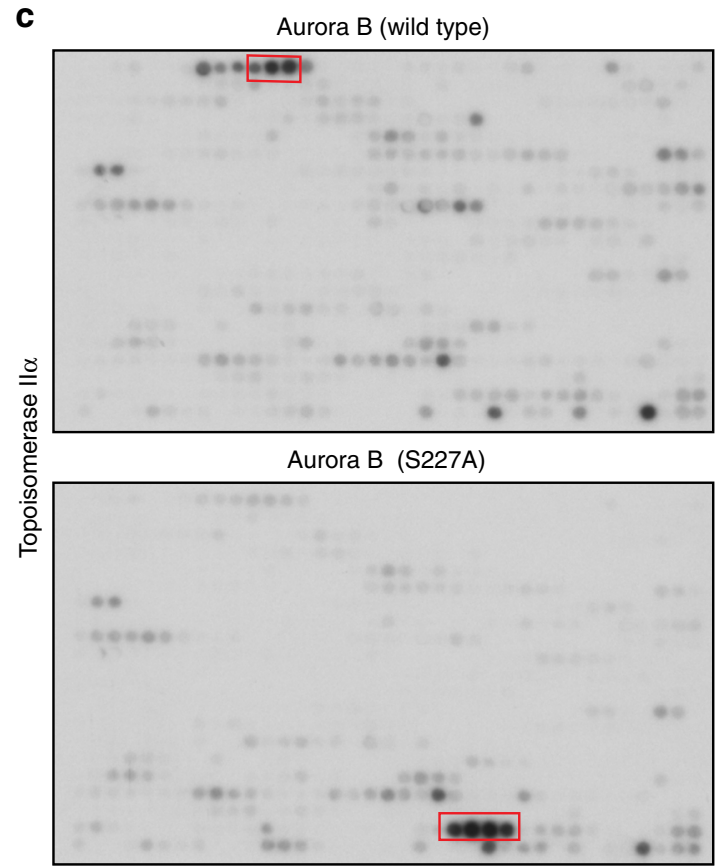

$\mathbf{f}$

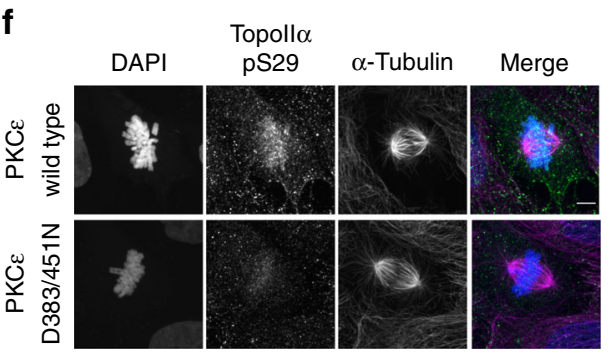

g

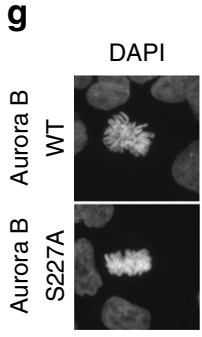

Topoll $\alpha$

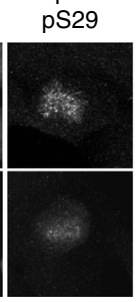

GFP-
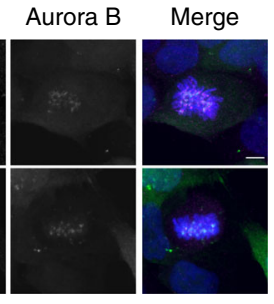

b
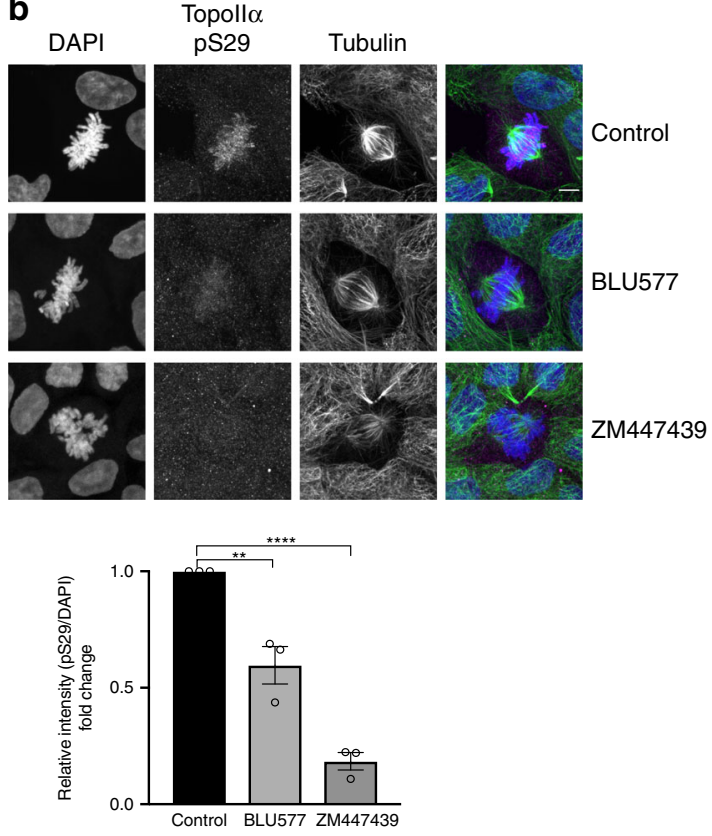

d

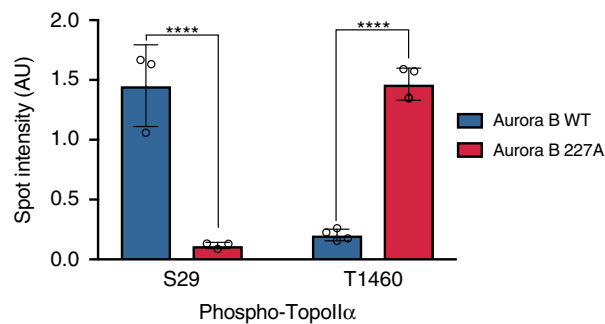

e $\mathrm{kDa}$

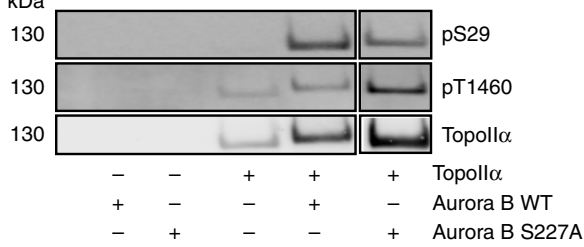

At the later abscission checkpoint, $\mathrm{PKC} \varepsilon$ is activated by 14-3-3 binding 9 and this is associated with Aurora B phosphorylation at S227 in the activation loop, causing a switch in substrate specificity and Borealin phosphorylation at $\mathrm{S} 165^{4}$. A protective role of PKC $\varepsilon$ at the abscission checkpoint is similarly the case at the metaphase-anaphase transition. In the presence of TopoIIa inhibition at metaphase, PKCe delays silencing of the SAC and anaphase entry by modulating dynein-mediated streaming of BubR1 away from the kinetochore ${ }^{2}$. This suggests that signalling through this pathway is important in both the resolution of metaphase 
Fig. 4 Aurora B switches substrate specificity to phosphorylate Topoll $\alpha$. a Immunofluorescent images of DLD1 cells stained for Topoll $\alpha$ phospho-S29 (magenta), a-tubulin (green) and DNA (blue). Images are representative of three independent experiments. Scale bar $=5 \mu \mathrm{m}$. $\mathbf{b}$ Representative still images of DLD1 cells stained with Topoll $\alpha$ pS29 (magenta), a-tubulin (green) and DNA (blue) after 30 min treatment with the PKC $\varepsilon$ inhibitor BLU577 (500 nM) or 15 min Aurora B inhibition with ZM447439 $(2 \mu \mathrm{M})$. Quantification of integrated pixel intensity measurements of Topollo pS29. Graph shows mean \pm SEM of three experiments where 20 cells were scored per condition (one-way ANOVA; ${ }^{\star \star} P=0.0034{ }^{\star \star \star \star} P=\leq 0.0001$; Control $1 \pm 0, B L U 5770.5967 \pm 0.08, Z M 447439$ $0.18 \pm 0.04)$ Scale bar $=5 \mu \mathrm{m}$. c Peptide array $(n=1)$ of full length Topoll $\alpha$ with recombinant Aurora B wild type (top panel) or Aurora B S227A (lower panel). d Quantification of Topoll $\alpha$ array spot intensity for S29 and T1460 peptides. Graph represents mean \pm SD of the intensity of spots highlighted in red in c $(n=$ 3 spots for S29, $n=4$ spots for T1460). (two-tailed Students' $t$ test; ${ }^{\star \star \star \star} P=5.17 \times 10^{-6}(\mathrm{~S} 29), P=1.4 \times 10^{-8}$ (T1460); S29: Aurora B WT 1.45 $\pm 0.34, \mathrm{~S} 227 \mathrm{~A}$ $0.12 \pm 0.03, T 1460$ : WT $0.2 \pm 0.05$, S227A $1.47 \pm 0.13$ ). Spot densitometry analysed by ImageJ software. e In vitro kinase assay of Topoll $\alpha$ with Aurora B wild type or S227A kinase. Topoll $\alpha$ was immunoblotted for phosphorylation at residues S29 and T1460. Immunoblot is representative of four independent experiments. f Representative images of DLD1 cells induced to express GFP-PKC $\varepsilon$ WT or D383/451N mutant stained for Topoll $\alpha$ pS29 (magenta) and tubulin (green). Quantification of integrated pixel intensity measurements of Topoll $\alpha$ pS29. Graph shows mean \pm SEM of three experiments where $\geq 20$ cells were scored per condition (two-tailed Students' $t$ test; ${ }^{\star \star} P=0.009$ ) Scale bar $=5 \mu \mathrm{m}$. $\mathbf{g}$ Representative images of DLD1 cells induced to express GFP-Aurora B WT or S227A mutant stained for Topoll $\alpha$ pS29 (magenta) and GFP-Aurora B (green). Quantification of integrated pixel intensity measurements of Topoll $\alpha$ pS29. Graph shows mean \pm SEM of three experiments where $\geq 10$ cells were scored per condition (two-tailed Students' $t$ test; ${ }^{\star \star \star} P=0.0008$ ) Scale bar $=5 \mu \mathrm{m}$.

catenation and delayed onset of anaphase. The ability of Aurora B S227A to phenocopy PKCe mutant behaviour is consistent with previous data indicating that Aurora B S227 is a substrate of the recombinant $\mathrm{PKC} \varepsilon$ kinase domain influencing substrate selection of Aurora $\mathrm{B}^{4}$. We herein provide direct evidence of PKC $\varepsilon$ phosphorylation of Aurora B S227 in mitosis, demonstrating that a PKCeAurora B signalling module plays a protective role at both cell cycle junctures.

We have previously reported the ability of Aurora B to switch substrate specificity in response to $\mathrm{PKC} \varepsilon$ phosphorylation to exit from the abscission checkpoint ${ }^{4}$. MD simulations suggest the phosphorylation of S227 makes a significant conformational change in the loop structure and the dynamics of the protein. This change in dynamics can potentially explain the changes in the substrate specificity compared with the constitutively active Aurora B pT232. This was supported by peptide docking followed by the $100 \mathrm{~ns}$ MD simulation of the TopoIIa S29 peptidebound Aurora B pS227/pT232 and the T1460 residue containing peptide-bound Aurora B pT232. The complexes remained stable throughout the course of the simulation. The bisphosphorylated B pS227/pT232 Aurora B could not accommodate the peptide containing $\mathrm{T} 1460$ residue while being able to accommodate the TopoIIa S29 peptide, the reciprocal is also true, providing further insight into the substrate switch. During the MD simulations, the phosphorylated forms of Aurora B were able to pull their respective substrate peptides towards the nucleotide-binding site and close to D200 to align for catalysis. This indicates that the changes in conformation of the kinase after phosphorylation of S227 are directly related to the selection of distinct substrates.

Cleavage by Caspase-7 proteolysis in the V3 hinge domain of $\mathrm{PKC} \varepsilon$, resulted in a small pool of constitutively active kinase domain. Other PKC family members including PKC $\delta, P K C \eta$, $\mathrm{PKC} \theta$ are similarly cleaved by Caspase in the V 3 hinge region to separate the regulatory domain and catalytically active kinase domain $^{21}$; however these responses are pro-apoptotic signals. The outcome of Caspase-7 cleavage of PKCe appeared to be different as we observed no evidence of an apoptotic programme being triggered. In fact, Basu et al. report that Caspase-7 dependent cleavage of PKCe in MCF7 cells protects from TNF-induced apoptosis $^{12}$. Caspase-7 has been implicated in mitotic progression; expression of the active form of the protease increases during mitosis and knockdown or inhibition of Caspase-7 in HepG2 cells prevents proliferation by arresting cells in mitosis ${ }^{22}$. This non-apoptotic role of Caspase-7 in mitosis is supported by a growing body of literature of alternative functions of Caspases including cell cycle regulation where, for example, Caspase cleavage of proteins such as p21 CIP1/WAF123, p27 KIP124,25, and
BubR $1^{26}$ have been reported to drive proliferation. Collectively the data indicate that PKCe is the critical target for Caspase-7 in this non-disjunction protective cell cycle pathway and that cleavage of PKCE to release the kinase domain is necessary and sufficient for the delay in the metaphase-anaphase transition as well as resolution of the catenation associated with this delay.

The mapping of the Caspase-7-PKCe-Aurora B cascade led us to test whether the catenane resolution pathway is directly influenced by the output of this cascade. TopoIIa mediates decatenation and has been identified previously as both a PKC substrate ${ }^{17,18}$, and an Aurora B substrate in vitro ${ }^{27}$ and a functional relationship between the two kinases and TopoIIa has been described in yeast $\left(\mathrm{PKC}^{17}\right.$, Aurora $\mathrm{B}^{28}$ ) and Drosophila ${ }^{20}$. While we cannot exclude PKCe as an upstream kinase which phosphorylates TopoIIa, inhibition with ZM447439 and expression of the Aurora B S227A mutant suggests this phosphorylation is predominantly carried out by Aurora B. PKC $\delta$, which is also cleaved by caspases to generate a free catalytic domain, modulates TopoIIa activity in $S$ phase in response to genotoxic stress, triggering Caspase-dependent apoptotic cell death ${ }^{29}$. Interestingly, Coelho et al. ${ }^{20}$ report that Aurora B localisation and activity at the centromere is dependent on the presence of TopoIIa for accurate bi-orientation and chromosome segregation. Further to this, Edgerton et al. ${ }^{28}$ demonstrated that Aurora B is recruited by the C-terminal domain of TopoIIa, independent of the enzyme's catalytic activity. We demonstrate that Topolla is a direct substrate of Aurora B and phosphorylation of TopoIIa enhances the decatenating ability of the enzyme required for the resolution pathway, however this interaction is independent of the catenation-associated delay to anaphase entry. Taken together, the data indicate a bifurcation of the described Caspase-7-PKCe-Aurora $\mathrm{B}$ pathway. One arm of this pathway signals a delay in anaphase entry through PKCe-Aurora B regulation of SAC silencing at the kinetochore in response to unresolved catenanes, whilst the other triggers phosphorylation of TopoII $a$ impacting catenane resolution.

In summary, the unravelling of the catenation-associated delay and resolution pathways operating through PKCe at the metaphase/anaphase transition, has revealed a series of distinctive events. There is a non-canonical, cell cycle coupled activation pathway operating through Caspase-7 resulting in PKCE cleavage. This produces a phosphorylated i.e., primed, catalytic domain which we demonstrate by ectopic expression and inducible $\mathrm{PKC} \varepsilon$ cleavage, is sufficient to implement the delay to anaphase entry triggered by ICRF193 treatment. Having previously established that Aurora B can be a downstream target of PKCe, we demonstrate here that the ability of Aurora B to switch substrate repertoire in response to phosphorylation at S227 is important for both the delay and resolution pathways. We provide evidence that two phospho-forms of Aurora B differentially phosphorylate 
a

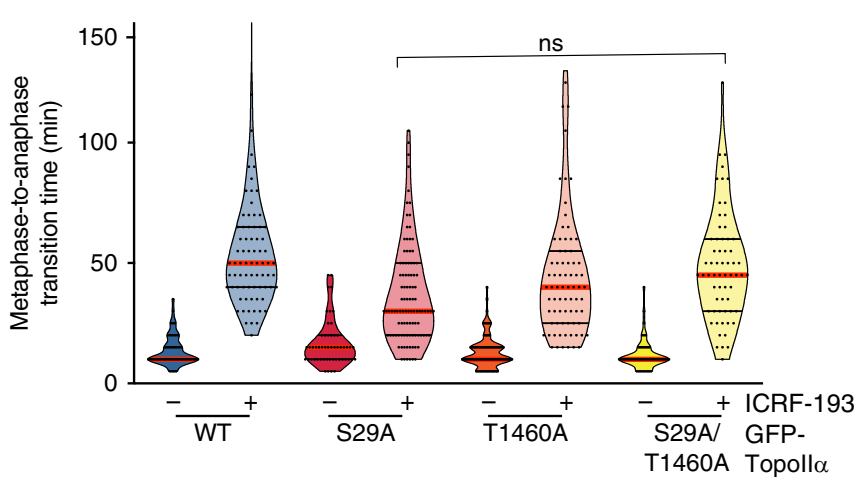

b

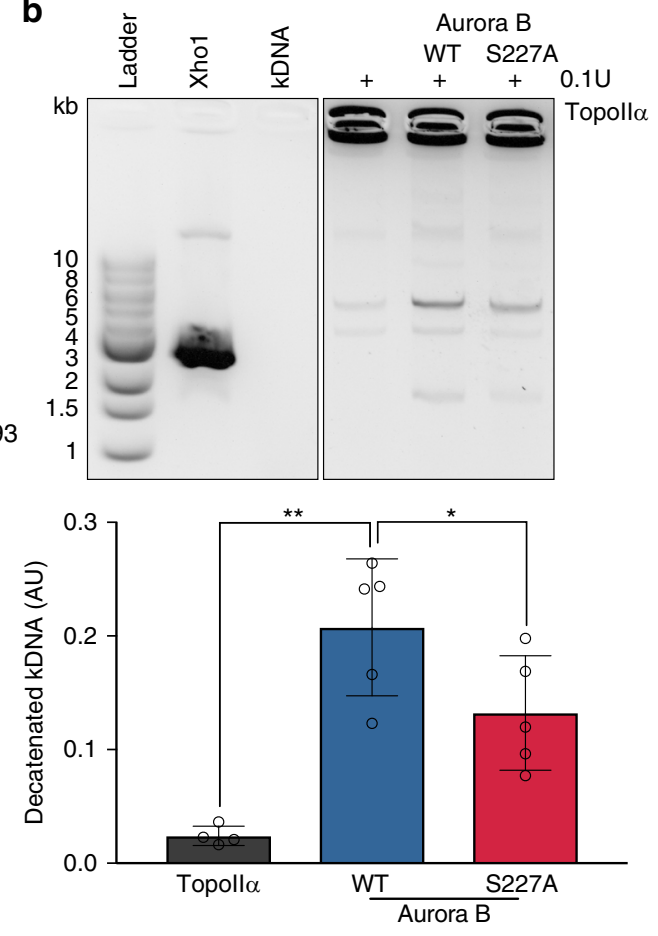

C
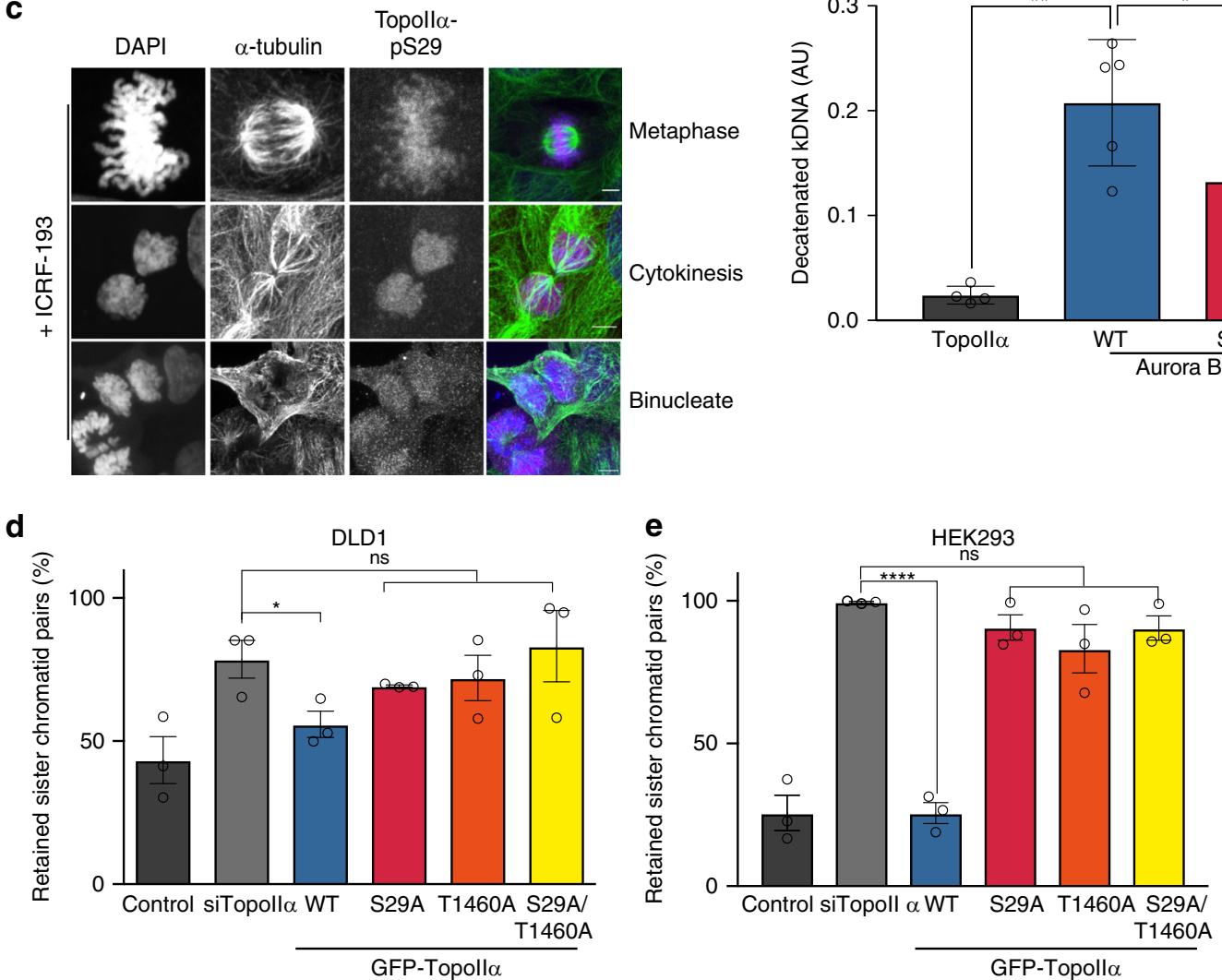

Fig. 5 Phosphorylation is required for enhanced Topoll $\alpha$ decatenation. a DLD1 cells induced to express GFP-Topolla wild type or mutants were assessed for the metaphase catenation response. Cells were treated $\pm 1 \mu \mathrm{M}$ ICRF193 immediately prior to time-lapse imaging and scored for the time to progress from metaphase to anaphase. The mean \pm SEM of three independent experiments is represented by the graph, $\geq 100$ cells per condition were analysed. (one-way ANOVA; WT + ICRF193 $55.6 \pm 2.23 \mathrm{~min}$ S29A + ICRF193 $44.18 \pm 6.69 \mathrm{~min}$, T1460A + ICRF193 $46.11 \pm 2.77 \mathrm{~min}, \mathrm{~S} 29 / \mathrm{T} 1460 \mathrm{~A}+$ ICRF193 $45.52 \pm 1.71 \mathrm{~min})$ b In vitro decatenation assay. Quantification of the amount of decatenated kDNA present after addition of Topollo and recombinant Aurora B (wild type or S227A). Graph represents the mean \pm SD of five independent experiments. (two-tailed Students' $t$ test, ${ }^{\star} P=0.012,{ }^{\star}{ }^{\star} P=0.0025$; Control $0.024 \pm 0.009$, WT $0.208 \pm 0.06$, S227A $0.132 \pm 0.05$ ). c Representative immunofluorescence images of DLD1 cells after $1 \mathrm{~h}$ treatment with ICRF193 (1 $\mu$ M) showing Topoll $\alpha$ pS29 (magenta), a-tubulin (green) and DNA (blue). Images are representative of three independent experiments. Scale bar $=5 \mu \mathrm{m}$. $\mathbf{d}$, e Catenation spread assay analysis. $\mathbf{d}$ DLD1 cells induced to express GFP-Topoll $\alpha$ wild type or mutants were scored for the per cent joined (catenated) chromatids. The mean \pm SEM of three experiments where $\geq 15$ cells per experiment were analysed is represented by the graph. (two-tailed Students' $t$ test; ${ }^{\star} P=0.047$; siControl 43.38\% \pm 8.22, siTopolla 78.64\% \pm 6.61 , WT 55.88\% \pm 4.58 , S29A 69.24\% \pm 0.36, T1460A 72.07\% \pm 7.94, S29/T1460A 83.17\% \pm 12.49 ). e HEK293 cells induced to express GFP-Topolla wild type or mutants were scored for the per cent joined (catenated) chromatids. The mean \pm SEM of three experiments where $\geq 15$ cells per experiment were analysed is represented by the graph (two-tailed Students' $t$ test; ${ }^{\star \star \star \star} P=\leq 0.0001$; siControl $25.66 \% \pm$ 6.17, siTopolla 99.57\% \pm 0.26 , WT 25.62\% \pm 3.63 , S29A 90.68\% \pm 4.44, T1460A 83.21\% \pm 8.47 , S29/T1460A 90.46\% \pm 4.25 ).

TopoIIa to directly affect its activation, specifically acting in the resolution pathway (Fig. 6).

\section{Methods}

Reagents. All reagents were purchased from Sigma-Aldrich unless otherwise stated. BLU577 was kindly provided by Dr Jon Roffey, Cancer Research Technology, UK.
Cell culture. All cell lines were obtained from ATCC and cultured in DMEM (Thermo Fisher Scientific) with 10\% fetal calf serum (Thermo Fisher Scientific). Tetracycline-inducible DLD1 (a kind gift from Prof Stephen Taylor, University of Manchester) were generated using the Flp-In ${ }^{\mathrm{Ts}} \mathrm{T}-\mathrm{Rex}^{\mathrm{TM}}$ system (Invitrogen) according to the manufacturer's instructions. For GFP-Aurora B, GFP-TopoIIa or GFP-PKC $\varepsilon$ expression, cells were depleted of endogenous protein by siRNA and cultured in DMEM containing $10 \%$ FCS and tetracycline $(100 \mathrm{ng} / \mathrm{ml})$ for $16 \mathrm{~h}$ prior 


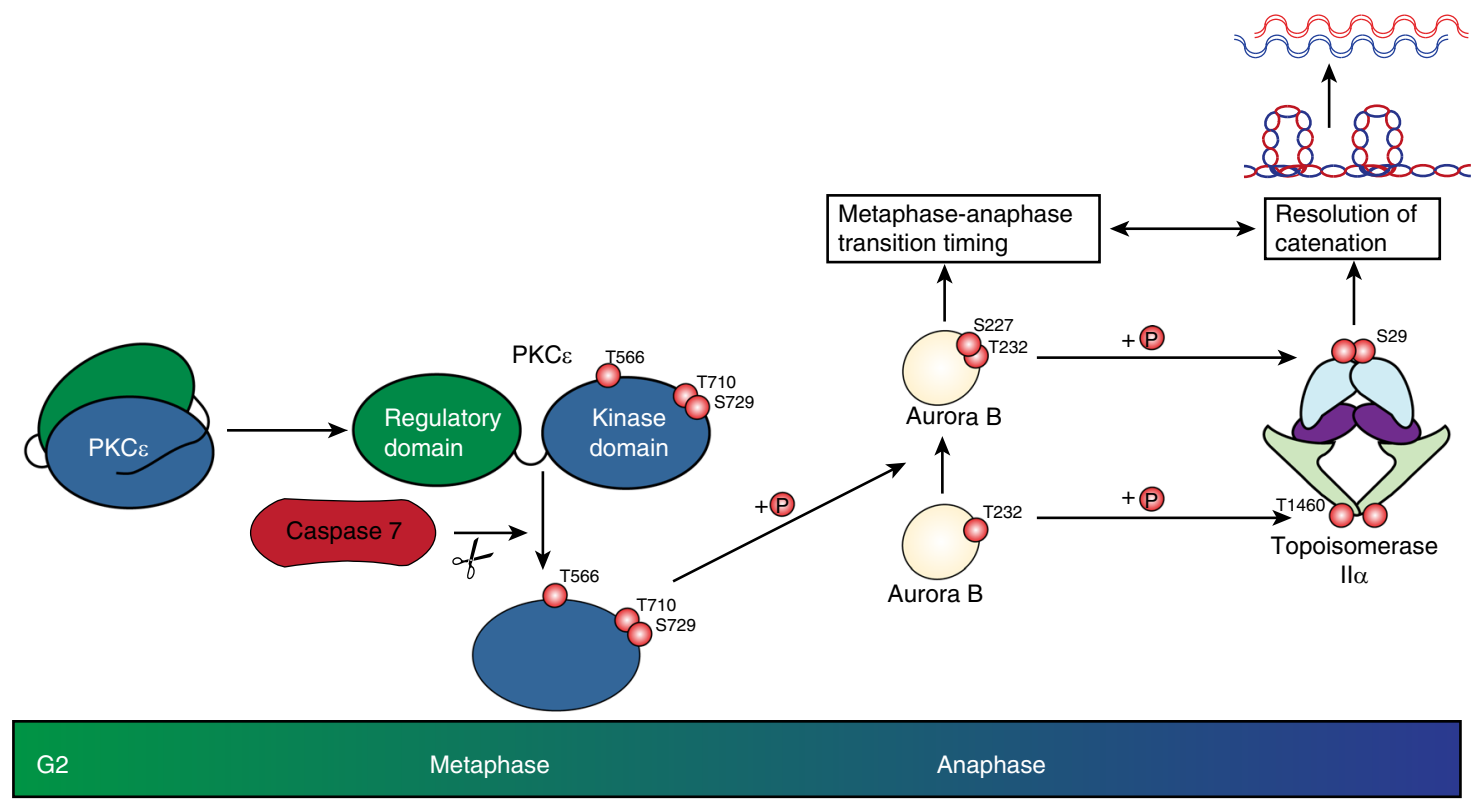

Fig. 6 Working model of non-canonical PKC $\varepsilon$ signalling in response to excess metaphase catenation. In mitosis, Aurora B switches substrate specificity in response to phosphorylation of S227 in the activation loop by a cell cycle-processed active fragment of PKC $\varepsilon$. Here, we show that this switch protects from chromosome non-disjunction by delaying anaphase entry and promoting Topollo-dependent resolution.

to assay. Cells were treated with inhibitors for the time/s stated. Cell lines were routinely tested for mycoplasma. For cell synchronisation, cells were treated with a double thymidine block ( $2.5 \mathrm{mM})$, released into pre-warmed, complete media for 6 $\mathrm{h}$ and arrested in G2/M by adding $9 \mu \mathrm{M}$ RO-3306 (CDK1 inhibitor) and $1 \mu \mathrm{M}$ ICRF193. Cells were released into mitosis by washing with complete media and the indicated inhibitors and monitored until they reached mitosis.

Plasmids. GFP-PKC $\varepsilon$ and TopoIIa-GFP (a kind gift from Dr Christian Mielke) cDNAs were cloned into pcDNA5/FRT/TO(Invitrogen) using the InFusion cloning kit (Clontech) as per the manufacturers' instructions. For recombinant protein production, pET-Duet-1 Aurora B:INCENP was a gift from Dr Jon Elkins, University of Oxford. Site-directed mutagenesis was completed using ChangeIT mutagenesis kit (Agilent) according to the manufacturers' instructions. All clones were sequence verified.

Primers. See supplementary methods (Supplementary Tables 1-3) for full list of primers used in this study.

SiRNA. For siRNA transfection, Lullaby (OZ Biosciences) was used according to manufacturers' recommendations; all siRNAs were used at a final concentration of $20 \mathrm{nM}$. The following SmartPOOLS were purchased from Dharmacon:

PKC $\varepsilon$ sil (D-004653-01 5'-GGGCAAAGAUGAAGUAUAU-3'), Caspase-3 (Cat. L-004307 5'-CCGACAAGCUUGAAUUUAU-3', 5'-CCACAGCACCUGG UUAUUA-3', 5'-GAAUUGAUGCGUAGAUGUUU- ${ }^{\prime}$ ', 5'-GCGAAUCAAUGG ACUCUGG-3') and Caspase-7 (L-004407 5'-GGGCAAAUGCAUCAUAAUA-3' ${ }^{\prime} 5^{\prime}$ GAUCAGGGCUGUAUUGAAG-3',5-UACCGUCCCUCUUCAGUAA-3', 5'-CCA GACCGGUCCUCGUUUG-3'). siTopoII $\alpha\left(5^{\prime}\right.$-GGUAACUCCUUGAAAGUAA- $3^{\prime}$, $5^{\prime}$-GGAGAAGAUUAUACAUGUA-3' ${ }^{\prime}, 5^{\prime}$-GAUGAACUCUGCAGGCUAA-3', $5^{\prime}$ CGAAAGGAAUGGUUAACUA- $3^{\prime}$ ) and siAuroraB (5'- AATTAGGGATCCCT TCTTTCC-3') were designed against the respective $3^{\prime}$ UTR to allow knockdown of endogenous protein with expression of ectopic GFP-tagged proteins. The remaining siControl oligonucleotides were purchased from Qiagen; cat. 1027310 (5'-AATTCT CCGAACGTGTCACGT-3')

Kinase assay. Kinase assays were conducted in $50 \mu \mathrm{l}$ reactions containing $20 \mathrm{mM}$ Tris pH7.5, $5 \mathrm{mM} \mathrm{MgCl} 2,0.5 \mathrm{mM}$ DTT, $0.2 \%$ Triton X-100, $100 \mu \mathrm{M}$ ATP. Reactions were incubated for $30 \mathrm{~min}$ at $37^{\circ} \mathrm{C}$ using $100 \mathrm{ng}-1 \mu \mathrm{g}$ of each recombinant protein per reaction. Reactions were terminated by addition of NuPAGE $4 \times$ LDS sample buffer (Thermo Fisher Scientific) prior to SDS-PAGE and western blotting with the appropriate phospho antibodies to detect kinase activity against specific phosphosites. GFP-PKCe proteins were immunoprecipitated from DLD1 cells and ATP consumption was measured by Kinase- $\mathrm{GLO}^{\mathrm{m}}$ as per manufacturer's instructions.

Peptide array. 15 mers of TopoII with a shift of two were arrayed on nitrocellulose by the Peptide Chemistry Laboratory of the Francis Crick Institute. Membranes were blocked in $0.2 \mathrm{mg}$ per ml BSA, $20 \mathrm{mM}$ Tris $\mathrm{pH} 7.5$, and $0.02 \%$
Tween-20 overnight. Membranes were subsequently incubated with the appropriate recombinant protein (Aurora B Wild type $(100 \mu \mathrm{g})$, Aurora B S227A $(100 \mu \mathrm{g})$ ), and $10 \mathrm{mM} \mathrm{MgCl}, 100 \mu \mathrm{M}\left[{ }^{32} \mathrm{P}\right]$-ATP $(5 \mu \mathrm{Ci}$ per $\mathrm{ml})$ for $10 \mathrm{~min}$ followed by extensive washing in $\mathrm{H}_{2} \mathrm{O}$ and acetic acid. Membranes were then exposed to film before spot intensity analysis using the ImageQuant TL7 (GE Lifesciences).

Chromatin fractionation. Cells were swelled in a hypertonic buffer $(10 \mathrm{mM}$ Tris pH7.5, $5 \mathrm{mM} \mathrm{MgCl}_{2}$, $1 \mathrm{mM}$ EGTA, $1 \mathrm{mM}$ DTT) for $20 \mathrm{~min}$ on ice before being lysed by 20 strokes through a $25 \mathrm{G}$ needle. The supernatant (S1) was collected as the cytosolic fraction and the pellet was lysed in 1\% Triton X-100 buffer (1\% Triton X-100, $150 \mathrm{mM} \mathrm{NaCl}, 50 \mathrm{mM}$ Tris pH7.4, protease inhibitor cocktail (Roche)) for $10 \mathrm{~min}$ on ice before separating the supernatant (S2) and chromatin containing pellet $(\mathrm{P} 1)$ by high-speed centrifugation $(15,000 \times g, 20 \mathrm{~min})$.

Triton X-100 fractionation. Cells were lysed in $5 x$ pellet volumes of $1 \%$ Triton X100 buffer ( $1 \%$ Triton X-100, $150 \mathrm{mM} \mathrm{NaCl}, 50 \mathrm{mM}$ Tris $\mathrm{pH} 7.4$, protease inhibitor cocktail (Roche)) for $10 \mathrm{~min}$ on ice before centrifugation $(13,000 \times g, 10 \mathrm{~min})$. The pellet was resuspended in 2X NuPAGE LDS sample buffer (Thermo Fisher Scientific).

Immunofluorescence and immunoblotting. For immunofluorescence experiments, cells were grown on $13 \mathrm{~mm}$, \#1.5 glass coverslips and fixed in $4 \%$ paraformaldehyde-PBS for $20 \mathrm{~min}$, followed by permeabilization in $0.5 \%$ Triton X100 for $5 \mathrm{~min}$ before blocking in a solution of $3 \%$ BSA/PBS. The following primary antibodies were used in these assays: mouse anti-TopoIIa (MAB4197, Millipore 1:300), rabbit anti-TopoII $\alpha$ phosphoSer29 (made in-house, 1:100), rabbit antiTopoIIa phosphoThr1460 (made in-house, 1:100), mouse anti-alpha tubulin (clone DM1A, T9026, Sigma, 1:1000), rabbit anti-PICH (H00054821-D01, Abnova, 1:300), mouse anti-Lap2B (611000, BD, 1:300), rabbit anti-Bub1 (Abcam, 1:100), rabbit anti-BubR1 (Abcam, 1:300), rabbit anti-MAD2 (Bethyl Antibodies, 1:300), human anti-centromere (Crest) (Antibodies Inc 1:300). Primary antibodies were detected with Alexa Fluor conjugated secondary antibodies diluted 1:1000 in 3\% BSA/PBS (Goat anti-mouse AlexaFluor 488-A11001; Goat anti-rabbit AlexaFluor 488-A11008; Goat anti-mouse AlexaFluor 555-A21422; Goat anti-rabbit AlexaFluor 555 Conjugated secondary antibody-A21428; Goat anti-mouse AlexaFluor 647-A32728; Goat anti-rabbit AlexaFluor 647-A21244; Goat anti-human AlexaFluor 647-A21445, Life technologies). All coverslips were mounted using ProLong Diamond with DAPI (Invitrogen).

For immunoblotting, cells were lysed in 1X NuPAGE LDS sample buffer (Thermo Fisher Scientific) and sonicated for $3 \times 10 \mathrm{~s}$ on ice. Proteins were separated by SDS-PAGE and transferred to PVDF membranes (Millipore). The following primary antibodies were used: mouse anti-Aurora B (AIM-1,611082, BD, 1:2000), rabbit anti-Aurora B phosphoThr232 (TA319253, Origene, 1:1000), rabbit anti-Aurora B phosphoSer227 (made in-house, 1:1000), mouse anti-alpha tubulin (clone DM1A, T9026, Sigma, 1:10000), mouse anti-TopoIIa (clone KiS1, MAB4197, Millipore 1:5000), rabbit anti-TopoIIa phosphoSer29 (made in-house, 1:1000), rabbit anti-TopoIIa phosphoThr1460 (made in-house, 1:1000), rabbit anti-Histone H3 (9715, Cell Signaling, 1:5000), rabbit anti-Histone H3 
phosphoSer10 (9701, Cell Signaling, 1:2000), rabbit anti-PKCe (sc-214, Santa Cruz, 1:1000), rabbit anti-PKC $\varepsilon$ phosphoSer729 (ab63387, Abcam 1:1000), rabbit antiPKC $\varepsilon$ phosphoThr566 (made in-house, 1:500), rabbit anti-PKC $\varepsilon$ phosphoThr710 (made in-house, 1:500), mouse anti-GFP (made in-house, 1:1000), rabbit antiCaspase-3 (AB1899, Millipore, 1:500), mouse anti-Caspase-7 (551238, BC Biosciences, 1:1000), mouse anti-GAPDH (clone 6C5, MAB374, Millipore, 1:5000), anti-cleaved PARP Asp241 (9541, Cell Signaling, 1:500). Mouse and rabbit HRPconjugated secondary antibodies (NA931 and NA934, GE Lifesciences) were used at dilutions between 1:5000 and 1:10000. Chemiluminescence was detected using Lumanata Classico western HRP substrate (Millipore) and imaged using the ImageQuant 4000 mini (GE Lifesciences). Band densitometry was carried out using ImageJ software and normalised to a loading control. Uncropped western blots are provided as Supplementary Fig. 9.

Proximity ligation assay. Cells were grown in eight-well chambered slides (Falcon) and fixed as for immunofluorescent imaging. PLA was conducted using a kit (Sigma-Aldrich) as per manufacturers instruction using the antibody pairs: antiGFP (rabbit)(Abcam, ab290), anti-TopoII (mouse)(Millipore) and anti-TopoIIa, anti-TopoIIa phospho-T1460 (rabbit)(made in-house). Non-specific IgG (rabbit sc-2027 and mouse sc-2025, Santa Cruz) were used in conjunction with antiTopoII a and anti-TopoIIa phospho-T1460 (respectively) as negative controls to demonstrate the specificity of the PLA reaction.

Microscopy. For live-cell time-lapse microscopy, cells were cultured on LabTek chambered coverglass slides (Nunc) in Leibovitz $\mathrm{CO}_{2}$-independent media (Thermo Fisher Scientific). A low light level inverted microscopy (Nikon TE2000) imaging system equipped with a laminar-flow heater to maintain a constant temperature of $37 \pm 0.001{ }^{\circ} \mathrm{C}$, a PlanFluor $40^{\prime}$ DIC lens and a Xenon lamp for fluorescent excitation. Images were taken using a high quantum efficiency CCD camera (Andor Ixon) every 5 min using MetaMorph (Version 6.3) software. Still images were taken using an inverted laser scanning confocal microscope (Carl Zeiss LSM780) equipped with a $63^{\prime}$ Plan-APOCHROMAT DIC oil-immersion objective using ZEN (Version $2.3 \mathrm{SP} 1$ ) software. Images were prepared for publication using ImageJ software.

Catenation spread assay. For measurement of metaphase catenation, cells were treated with siSgol for $24 \mathrm{~h}$, followed by $1 \mathrm{~h}$ treatment with nocodazole to collapse the mitotic spindle, to aid spreading. Cells were collected by shaking off the mitotic cells and resuspended in a hypotonic solution of $75 \mathrm{mM} \mathrm{KCl}$ and incubated at $37^{\circ} \mathrm{C}$ for $30 \mathrm{~min}$ to expand the cell. Cells were then resuspended in 3:1 methanolacetic acid and fixed overnight at $-20^{\circ} \mathrm{C}$. Cells were then spread onto glass slides by dropping from $1 \mathrm{~m}$ height. For assays where TopoIIa was reintroduced, recombinant TopoIIa ( $1 \mathrm{U} / \mu \mathrm{l}$, TopoGen) was incubated in the hypotonic step where the cell membrane becomes hyperpermeable. The hypotonic buffer used here contained 5 $\mathrm{mM}$ Tris-Cl, pH 8.0, $75 \mathrm{mM} \mathrm{KCl}, 10 \mathrm{mM} \mathrm{MgCl} 2,0.5 \mathrm{mM}$ ATP, $0.5 \mathrm{mM}$ dithiothreitol. We confirmed by video microscopy that there was no significant difference between the time that all samples had been arrested in mitosis at the start of the assay. Images processed using ImageJ software, and scored manually after blinding.

Immunofluorescent intensity profiles. TopoII $\alpha$ pS29 signal intensity was quantified using a custom-built script and the commercial software package MATLAB (MATLAB 2016a, MathWorks). The background pS29 signal for each cell was subtracted and the mitotic chromosomes were segmented by Otsu's method of thresholding of the DAPI channel. Subsequently, the pS29 signal intensity was normalized to the DAPI signal intensity and DAPI area to account for potential differences in chromatin condensation. At least ten images were analysed and the mean and S.E.M. of at least three independent experiments was quantified.

Expression and purification of recombinant protein. Recombinant Aurora B (WT and S227A) and PKCE-kinase domain were expressed and purified as previously described ${ }^{4}$. Aurora B WT and S227A proteins were assessed for their phosphorylation state (pS227 and pT232) and kinase activity against the substrate Histone $\mathrm{H} 3 \mathrm{~S} 10$ prior to use in all assays. Upon highly efficient production (i.e., high concentration) both sites become phosphorylated in vitro.

Kinetoplast DNA decatenation assay. For in vitro assessment of TopoIIa decatenation efficiency, the TopoGEN kinetoplast DNA (kDNA) assay was utilised with the following deviations to the manufacturers' instructions. Recombinant TopoIIa was incubated with recombinant Aurora B WT (pS227/pT232) or Aurora B S227A (pT232) at $30^{\circ} \mathrm{C}$ for $30 \mathrm{~min}$. Reactions contained $0.1 \mathrm{U}$ recombinant TopoIIa, $50 \mathrm{ng}$ of recombinant Aurora B, $100 \mathrm{nM}$ ATP, and $1 \mathrm{X}$ reaction buffer (Topogen) made up to $20 \mu \mathrm{l}$ with kinase dilution buffer. Reactions were terminated by addition of DNA gel loading dye (Thermo Fisher). kDNA was separated by electrophoresis on $1 \%$ agarose gel containing GelRed $^{\text {tw }}$ fluorescent DNA stain. Images were captured on UVP BioDoc-It2 imaging system using VisionWorks analysis software (Analytik Jena), and the kDNA decatenation quantified by calculating band densitometry using ImageJ analysis software.
Topoll $\alpha$ extraction and decatenation assay. HEK293 cells were induced to express GFP-TopoII $\alpha$ for $24 \mathrm{~h}$ while endogenous TopoII $\alpha$ was depleted with siRNA. Cells were twice pelleted and resuspended in ice-cold TEMP buffer $(10 \mathrm{mM}$ Tris pH7.5, $1 \mathrm{mM}$ EDTA, $4 \mathrm{mM} \mathrm{MgCl}_{2}, 0.5 \mathrm{mM}$ PMSF) before being left on ice for $10 \mathrm{~min}$. Lysates were homogenised by ten strokes through a $25 \mathrm{G}$ needle before nuclei were pelleted by centrifugation $(1500 \times g, 10 \mathrm{~min})$. The nuclear pellet was resuspended in TEMP buffer and washed, then resuspended in 4 pellet volumes of TEP buffer (10 mM Tris pH7.5, $1 \mathrm{mM}$ EDTA, $0.5 \mathrm{mM}$ PMSF) and an equal volume of $1 \mathrm{M} \mathrm{NaCl}$ added. Preparations were vortexed and left on ice for $60 \mathrm{~min}$. Finally, nuclear preparations were centrifuged at $4{ }^{\circ} \mathrm{C}$ for $15 \mathrm{~min}$ at $15,000 \times g$. Supernatants were diluted with $4 \mathrm{X}$ NuPAGE LDS sample buffer and immunoblotted for TopoIIa levels. TopoIIa levels were equalised prior to use in the TopoGEN kinetoplast DNA assay as above.

Recapitulating PKC $\varepsilon$ cleavage. To assess the effect of recapitulating PKC $\varepsilon$ cleavage on the metaphase-anaphase transition time, DLD1 GFP-PKCE TEV D383/451 N expressing pmCherry-H2B cells were transfected with siPKCe, after $24 \mathrm{~h}$ doxycycline $(100 \mathrm{ng} / \mathrm{ml})$ was added and incubated at $37^{\circ} \mathrm{C}$ and $10 \% \mathrm{CO}_{2}$ for $16 \mathrm{~h}$. Cells were incubated for $3 \mathrm{~h}$ with $500 \mathrm{nM}$ nocodazole to arrest the cells in prometaphase, followed by a further 2 -h incubation with $100 \mathrm{ng}$ rapamycin/ml to drive chemically induced dimerisation of TEV, and, as a result, PKC $\varepsilon$ cleavage. Media were aspirated and cells were washed three times with pre-warmed media to release the prometaphase arrest. Media were then replaced with $500 \mu$ l Leibovitz $\mathrm{CO}_{2}$-independent media (Gibco) $\pm 1 \mu \mathrm{M}$ ICRF193. Live-cell time-lapse images were obtained as above.

Homology modelling. The enzyme structure was obtained by homology modelling using SwissModel web server with the same amino acid sequence with two different templates of $4 \mathrm{AF} 3$ with $99.69 \%$ sequence identity and $5 \times 3 \mathrm{~F}$ with $31.91 \%$ sequence identity to the target amino acid sequence with Uniprot FASTA code Q96GD4. The obtained model using $4 \mathrm{AF} 3$ as the template excludes the $\mathrm{N}$-terminal and the second model was applied to amend the structure of the enzyme. The generated enzyme structure was considered in the presence of IN-box segment of INCENP, ATP, and $\mathrm{MG}^{2+}$ ions in two separate states of mono- and bis-phosphorylated forms by phosphorylation of Thr232 and Ser277 residues located in the loop (residues 220-250).

Molecular dynamics simulations for dominant conformations. A total of 100 -ns molecular dynamics simulations by AMBER 16 were performed for each system after minimising them with and without restraint. This was done in two stages with 2500 cycles of steepest descent followed by 2500 cycles of conjugate gradient minimisation and heating up to $310 \mathrm{~K}$ within $500 \mathrm{ps}$ and equilibrating for $1 \mathrm{~ns}$ using. The cutoff radius of non-covalent interactions was set to $12 \AA$. Also, periodic boundary conditions, particle-mesh Ewald method, to calculate the infinite electrostatics without truncating the parameters, and SHAKE algorithm, to consider all bonds in which the hydrogen atom was present in a fixed state and the others in their equilibrium values, were employed. The force fields parameters for the phosphorylated amino acids were generated using the ANTECHAMBER module of the AMBER program. Ten dominant conformation structures after downsampling of the obtained MD trajectories were extracted using MDAnalysis to run molecular docking.

Peptide-protein molecular docking. To complement the experimental characterisation of the protein-peptide complexes, we determined the peptide binding site in the protein and mode of interaction between the peptides and their corresponding protein kinase in the mono- and bis-phosphorylated states of Aurora B kinase using HPEPDOCK web server and Pep-SiteFinder service to run peptide-protein molecular docking and finding the key residues respectively. The peptide containing TopoIIa T1460 residue (QKPDPAKTKNRRKRKP) and TopoIIa S29 peptide (NEDAKKRLSVERIYQKK) were considered as the peptide substrates for monophosphorylated (pT232) and bis-phosphorylated (pS227/ pT232) forms of the enzyme, respectively.

Molecular dynamics simulations of protein-peptide complexes. A total of 100 ns molecular dynamics simulations by AMBER 16 were performed for the best poses of the peptides, located in the localised binding site by the above approaches, in complex with the enzymes. The parameters were considered as mentioned in the first round of MD simulations performed to extract the dominant conformations of mono and bis-phosphorylated Aurora B kinase.

Principal component analysis (PCA). PCA has been used to investigate the correlations among various important regions of the complexes in the course of MD simulations and to distinguish functional motions from the thermal and accidental motions. The fluctuations of the residues in critical regions were monitored using three different modes of PCA (PC1, PC2, and PC3).

Statistical analysis. For experiments where the data includes more than two conditions, a one-way ANOVA using multiple comparisons was used, in all other cases an unpaired $t$ test was used for analysis. Prism software (Graphpad) was used for all calculations. The level of statistical significance is represented as follows: $\mathrm{ns}=P>0.05,{ }^{*} P \leq 0.05,{ }^{* *} P \leq 0.01,{ }^{* * *} P \leq 0.001$ and ${ }^{* * * *} P \leq 0.0001$ 
Reporting summary. Further information on research design is available in the Nature Research Reporting Summary linked to this article.

\section{Data availability}

The data that support the findings of this study are available from the corresponding author upon reasonable request.

\section{Code availability}

Custom code developed for the immunofluorescence intensity profiling is available upon request.

Received: 7 March 2018; Accepted: 21 February 2020;

Published online: 13 March 2020

\section{References}

1. Özer, Ö. \& Hickson, I. D. Pathways for maintenance of telomeres and common fragile sites during DNA replication stress. Open Biol. 8, 180018 (2018).

2. Brownlow, N., Pike, T., Zicha, D., Collinson, L. \& Parker, P. J. Mitotic catenation is monitored and resolved by a PKCe-regulated pathway. Nat. Commun. 5, 5685 (2014).

3. Carmena, M., Wheelock, M., Funabiki, H. \& Earnshaw, W. C. The chromosomal passenger complex (CPC): from easy rider to the godfather of mitosis. Nat. Publ. Group 13, 789-803 (2012).

4. Pike, T., Brownlow, N., Kjaer, S., Carlton, J. \& Parker, P. J. PKCE switches Aurora B specificity to exit the abscission checkpoint. Nat. Commun. 7, 13853 (2016).

5. Carlton, J. G., Caballe, A., Agromayor, M., Kloc, M. \& Martin-Serrano, J. ESCRT-III governs the Aurora B-mediated abscission checkpoint through CHMP4C. Science 336, 220-225 (2012).

6. Capalbo, L. et al. The chromosomal passenger complex controls the function of endosomal sorting complex required for transport-III Snf7 proteins during cytokinesis. Open Biol. 2, 120070-120070 (2012).

7. Martini, S. et al. PKCE controls mitotic progression by regulating centrosome migration and mitotic spindle assembly. Mol. Cancer Res. 16, 3-15 (2018).

8. Chan, K. L. \& Hickson, I. D. New insights into the formation and resolution of ultra-fine anaphase bridges. Semin. Cell Dev. Biol. 22, 906-912 (2011).

9. Saurin, A. T. et al. The regulated assembly of a PKCE complex controls the completion of cytokinesis. Nat. Cell Biol. 10, 891-901 (2008).

10. van Eis, M. J. et al. 2,6-Naphthyridines as potent and selective inhibitors of the novel protein kinase C isozymes. Bioorg. Med. Chem. Lett. 21, 7367-7372 (2011).

11. Steinberg, S. F. Structural basis of protein kinase C isoform function. Physiol. Rev. 88, 1341-1378 (2008).

12. Basu, A. et al. Proteolytic activation of protein kinase $\mathrm{C}-\varepsilon$ by caspase-mediated processing and transduction of antiapoptotic signals. J. Biol. Chem. 277, 41850-41856 (2002).

13. Wang, L. H. C., Mayer, B., Stemmann, O. \& Nigg, E. A. Centromere DNA decatenation depends on cohesin removal and is required for mammalian cell division. J. Cell Sci. 123, 806-813 (2010).

14. Sen, N. et al. Physical proximity of sister chromatids promotes Top2 dependent intertwining. Mol. Cell 64, 134-147 (2016).

15. Sonntag, T. \& Mootz, H. D. An intein-cassette integration approach used for the generation of a split TEV protease activated by conditional protein splicing. Mol. BioSyst. 7, 2031-2039 (2011).

16. Williams, D. J., Puhl, H. L. \& Ikeda, S. R. Rapid MOdification of Proteins Using A Rapamycin-inducible tobacco etch virus protease system. PLoS ONE 4, e7474 (2009).

17. Mouchel, N. A. P. \& Jenkins, J. R. The identification of a functional interaction between PKC and topoisomerase II. FEBS Lett. 580, 51-57 (2005).

18. Wells, N. J., Fry, A. M., Guano, F., Norbury, C. \& Hickson, I. D. Cell cycle phase-specific phosphorylation of human topoisomerase II alpha. Evidence of a role for protein kinase C. J. Biol. Chem. 270, 28357-28363 (1995).

19. Sahyoun, N. et al. Protein kinase C phosphorylates topoisomerase II: topoisomerase activation and its possible role in phorbol ester-induced differentiation of HL-60 cells. Proc. Natl Acad. Sci. 83, 1603-1607 (1986).

20. Coelho, P. A. et al. Dual role of topoisomerase II in centromere resolution and Aurora B activity. PLoS Biol. 6, e207-e220 (2008).

21. Fischer, U., Jänicke, R. U. \& Schulze-Osthoff, K. Many cuts to ruin: a comprehensive update of caspase substrates. Cell Death Differ. 10, 76-100 Jan. (2003).
22. Hashimoto, T., Yamauchi, L., Hunter, T., Kikkawa, U. \& Kamada, S. Possible involvement of caspase-7 in cell cycle progression at mitosis. Genes Cells 13, 609-621 (2008)

23. Woo, M. et al. Caspase- 3 regulates cell cycle in B cells: a consequence of substrate specificity. Nat. Immunol. 4, 1016-1022 (2003).

24. Frost, V., Al-Mehairi, S. \& Sinclair, A. J. Exploitation of a non-apoptotic caspase to regulate the abundance of the cdkI p27(KIP1) in transformed lymphoid cells. Oncogene 20, 2737-2748 (2001).

25. Frost, V., Delikat, S., Al-Mehairi, S. \& Sinclair, A. J. Regulation of p27KIP1 in Epstein-Barr virus-immortalized lymphoblastoid cell lines involves nonapoptotic caspase cleavage. J. Gen. Virol. 82, 3057-3066 (2001).

26. Kim, M. et al. Caspase-mediated specific cleavage of BubR1 is a determinant of mitotic progression. Mol. Cell. Biol. 25, 9232-9248 (2005).

27. Morrison, C. et al. Proteomic analysis of human metaphase chromosomes reveals topoisomerase II alpha as an Aurora B substrate. Nucleic Acids Res. 30 , 5318-5327 (2002)

28. Edgerton, $\mathrm{H}$. et al. A noncatalytic function of the topoisomerase II CTD in Aurora B recruitment to inner centromeres during mitosis. J. Cell Biol. 213, 651-664 (2016).

29. Yoshida, K. et al. Protein kinase $\mathrm{C}$ activates topoisomerase II to induce apoptotic cell death in response to DNA damage. Mol. Cell. Biol. 26, 3414-3431 (2006)

\section{Acknowledgements}

This work was supported by the Francis Crick Institute, which receives its core funding from Cancer Research UK (FC001130), the UK Medical Research Council (FC001130) and the Wellcome Trust (FC001130). We thank all of the Francis Crick Institute core facilities for valuable support throughout this project, in particular, the light microscopy, peptide chemistry and protein production facilities. We thank Dr Mathias Cobbaut for helpful discussions and Dr Jeremy Carlton for critically reading the manuscript.

\section{Author contributions}

T.N.S., J.R.K., N.B., K.M.R., F.F., and P.J.P. devised experiments, J.R.K., T.N.S., S.J., S.M., and N.L. carried out experiments. D.J. and S.F. synthesised peptides and arrays, S.K prepared and purified recombinant proteins. K.M.R., T.N.S., and P.J.P. wrote the paper

\section{Competing interests}

The authors declare no competing interests.

\section{Additional information}

Supplementary information is available for this paper at https://doi.org/10.1038/s41467 020-15163-6.

Correspondence and requests for materials should be addressed to P.J.P. or T.N.S

Peer review information Nature Communications thanks Alakananda Basu and the other, anonymous, reviewer(s) for their contribution to the peer review of this work. Peer reviewer reports are available.

Reprints and permission information is available at http://www.nature.com/reprints

Publisher's note Springer Nature remains neutral with regard to jurisdictional claims in published maps and institutional affiliations.

Open Access This article is licensed under a Creative Common Attribution 4.0 International License, which permits use, sharing, adaptation, distribution and reproduction in any medium or format, as long as you give appropriate credit to the original author(s) and the source, provide a link to the Creative Commons license, and indicate if changes were made. The images or other third party material in this article are included in the article's Creative Commons license, unless indicated otherwise in a credit line to the material. If material is not included in the article's Creative Commons license and your intended use is not permitted by statutory regulation or exceeds the permitted use, you will need to obtain permission directly from the copyright holder. To view a copy of this license, visit http://creativecommons.org/ licenses/by/4.0/.

(C) The Author(s) 2020 